University of South Carolina

Scholar Commons

\title{
State of Charge and Loss of Active Material Estimation of a Lithium Ion Cell under Low Earth Orbit Condition using Kalman Filtering Approaches
}

\author{
Saeed Khaleghi Rahimian \\ Sean Rayman \\ University of South Carolina - Columbia, rayman@cec.sc.edu \\ Ralph E. White \\ University of South Carolina - Columbia, white@cec.sc.edu
}

Follow this and additional works at: https://scholarcommons.sc.edu/eche_facpub

Part of the Chemical Engineering Commons

\author{
Publication Info \\ Published in Journal of The Electrochemical Society, Volume 159, Issue 6, 2012, pages A860-A872. \\ (C) Journal of The Electrochemical Society (2012), The Electrochemcial Society. \\ (C) The Electrochemical Society, Inc. 2012. All rights reserved. Except as provided under U.S. copyright law, \\ this work may not be reproduced, resold, distributed, or modified without the express permission of The \\ Electrochemical Society (ECS). The archival version of this work was published in Journal of The \\ Electrochemical Society. \\ Publisher's Version: http://dx.doi.org/10.1149/2.098206jes \\ Rahimian, S. K., Rayman, S., \& White, R. E. (April 18, 2012). State of Charge and Loss of Active Material \\ Estimation of a Lithium Ion Cell under Low Earth Orbit Condition using Kalman Filtering Approaches. \\ Journal of The Electrochemical Society, 159 (6), A860 - A872. http://dx.doi.org/10.1149/2.098206jes
}

This Article is brought to you by the Chemical Engineering, Department of at Scholar Commons. It has been accepted for inclusion in Faculty Publications by an authorized administrator of Scholar Commons. For more information, please contact digres@mailbox.sc.edu. 


\title{
State of Charge and Loss of Active Material Estimation of a Lithium Ion Cell under Low Earth Orbit Condition Using Kalman Filtering Approaches
}

\author{
Saeed Khaleghi Rahimian, ${ }^{*}$ Sean Rayman, ${ }^{* *}$ and Ralph E. White ${ }^{* * *, z}$ \\ Department of Chemical Engineering, University of South Carolina, Columbia, South Carolina 29208, USA
}

\begin{abstract}
The state of charge (SOC) and the loss of active material of the electrodes of a Li ion cell under Low Earth Orbit condition (LEO) have been estimated using Kalman filtering methods, by means of the physics-based single particle (SP) model. Zero mean Gaussian noise was added to the charge-discharge curves obtained by the SP model to generate synthetic data. Afterwards, nonlinear Filtering approaches including Extended Kalman Filtering (EKF) and Unscented Kalman Filtering (UKF) were applied to predict the true SOC and the electrodes' degradation, by minimizing the measurement residuals between the model prediction and the synthetic data. The results indicated that UKF is a far superior candidate than EKF for the SOC estimation for a Li-ion cell during the cycling. Moreover, the proposed method is able to predict the loss of active material for each electrode during the cell life. (C) 2012 The Electrochemical Society. [DOI: 10.1149/2.098206jes] All rights reserved.
\end{abstract}

Manuscript submitted December 7, 2011; revised manuscript received March 7, 2012. Published April 18, 2012.

Accurate state of charge (SOC) estimation is a key element in battery management system and cell life prediction, because the SOC provides the amount of available capacity inside the cell at any given instant. The majority of the studies have applied empirical models due to computation burden of the physics-based models. ${ }^{1-12}$ Verbrugge et al. determined the SOC and state of health $(\mathrm{SOH})$ of batteries in the context of electric vehicles by updating the parameters of semiempirical equivalent circuit models (ECM) recursively. ${ }^{1-4}$ An empirical model based on pole-placement method in association with Extended Kalman Filtering (EKF) $)^{5-7}$ and Sigma-point Kalman Filtering $(\mathrm{SPKF})^{8,9}$ was applied by Plett to characterize the SOC of a $\mathrm{Li}$ ion polymer cell. Lee et al. developed an SOC estimation approach that relied on a reduced order EKF and the mathematical modeling based on the ECM and the impedance spectrum of a Li ion battery. ${ }^{10} \mathrm{An}$ ECM with varying parameters that are linear spline functions of SOC was utilized by $\mathrm{Hu}$ et al. with the purpose of the SOC prediction for automotive applications. ${ }^{11}$ Recently, F. Sun et al. proposed an adaptive Unscented Kalman Filtering (UKF) with a zero-state hysteresis battery model structure for online estimation of the SOC of a Li-ion battery for electric vehicles. ${ }^{12}$ Although the aforementioned works were able to determine the SOC accurately in the applied domain with reasonable computation time, none of them provide any insight into what is happening inside the cell and the parameters of the models have little physical significance. As a result, improving the cell design and performance remains a remarkable issue.

Santhanagopalan and White have published two papers for online estimation of the SOC of a $\mathrm{Li}$ ion cell implementing filtering methods by means of physics-based models. ${ }^{13,14}$ The first work used the physics based single particle (SP) model and the EKF method ${ }^{13}$ while the second paper includes the utilization of a rigorous electrochemical cell model and the UKF approach ${ }^{14}$ for predicting the SOC of the cell. Smith et al. designed a linear Kalman filtering based on a reduced order electrochemical model in order to estimate internal battery potentials, concentration gradient and the SOC. ${ }^{15}$ They showed that with 4 to 7 states, the filter has a computation time comparable to empirical ECMs commonly employed. Another work that applied a physicsbased model EKF for the SOC estimation of a Li ion battery is the study by Domenico et al. published recently. ${ }^{16}$ They employed an electrode-average concentration approximation in order to simplify the full order electrochemical model. None of the studies that have applied a physics-based model up to now have considered cycling condition and capacity loss of the cell.
In this work the physics-based SP model accompanied by the $\mathrm{EKF}^{27}$ and the $\mathrm{UKF}^{29}$ methods is used to estimate the SOC and the loss of active material of the electrodes of a $\mathrm{Li}$ ion cell under Low Earth Orbit (LEO) cycling condition. Three different capacity fade mechanisms are studied thoroughly and the results of the filtering techniques are compared. Due to the highly nonlinear nature of the dynamic system, the EKF is not able to predict the state variables accurately while the UKF tracks the states with good agreement for all case studies. Furthermore, the computation times show that the UKF method is comparable with the EKF in the first two cases and even faster in the final case.

\section{Physics-Based Model}

This section describes the details of the SP model that consists of the capacity fade phenomena due to a film formation on the anode, and the loss of active material of both electrodes. Degradation mechanisms during charge and discharge are also addressed. Finally, determination of the limiting electrode, the LEO cycling protocol, and a general form of the dynamic system will be presented.

Single particle model with capacity fade.- A simplified physicsbased so-called single particle (SP) ${ }^{17}$ model is used to predict the charge-discharge curves of the cell. The SP model considers each electrode as a single spherical particle whose area represents the porous electrode active surface area. Moreover, the concentration and potential distributions in the electrolyte phase are ignored which restricts the model usage for low rate operation $(\leq 1.0 \mathrm{C})$ (e.g. LEO condition). ${ }^{18}$ The thermal effects are also assumed to be negligible. These simplifying assumptions are made to allow us obtain a model that can be used with much less computation cost relative to more sophisticated models such as the pseudo two dimensional model. ${ }^{19}$

The solid phase diffusion equation in spherical particles is simplified by using a two-term polynomial approximation for each electrode as follows ${ }^{20,21}$ :

$$
\begin{aligned}
& \text { Cathode: } \\
& \begin{array}{c}
\frac{d x_{p, a v g}}{d t}=\frac{-3 J_{p}}{F R_{p} c_{p, \max }}, \quad J_{p}=\frac{I_{a p p}}{\omega_{p} S_{p}^{0}}, \quad \omega_{p}=\frac{l_{p}(t)}{l_{p}^{0}} \\
x_{p, \text { surf }}-x_{p, a v g}=\frac{-J_{p} R_{p}}{5 F D_{s, p} c_{p, \max }}
\end{array}
\end{aligned}
$$

\footnotetext{
*Electrochemical Society Student Member.

${ }^{* *}$ Electrochemical Society Member.

${ }^{* * *}$ Electrochemical Society Fellow.

${ }^{\mathrm{z}}$ E-mail: white@cec.sc.edu
}

Anode:
$\frac{d x_{n, a v g}}{d t}=\frac{-3 J_{n}}{F R_{n} c_{n, \max }}, \quad J_{n}=\frac{-I_{a p p}}{\omega_{n} S_{n}^{0}}-J_{s}, \quad \omega_{n}=\frac{l_{n}(t)}{l_{n}^{0}}$ 


$$
x_{n, \text { surf }}-x_{n, a v g}=\frac{-J_{n} R_{n}}{5 F D_{s, n} c_{n, \max }}
$$

where $x_{i, a v g}$, electrode's SOC, is the ratio of the solid average concentration to the maximum solid concentration for each electrode $\left(c_{i, \max }\right)$, $x_{i, s u r f}$ is the ratio of the solid surface concentration to the maximum solid concentration and $l_{i}(t)$ is the electrode loading, that is the mass of active material in the electrode. The $\mathrm{Li}$ ion mole balance is discussed in Appendix A. Since the side reaction occurs near the surface of the negative electrode, the current balance for the negative electrode includes the side reaction current density, $J_{s}$, which is calculated using cathodic Tafel kinetics by assuming an irreversible reaction in which the amount of lithium deposited is very small and reacts quickly with the solvent:

$$
J_{s}=-i_{0 f} \exp \left(\frac{-\alpha_{c, f} F}{R_{g} T} \eta_{s}\right)
$$

where $\eta_{s}$, the side reaction over potential, is expressed as :

$$
\eta_{s}=\phi_{n}-U_{\text {ref,f }}+\frac{I_{a p p}}{S_{n}} R_{f i l m}
$$

The film resistance $R_{\text {film }}$ in Eq. 4 is initially due to the solid electrolyte interphase (SEI) resistance and then due to the resistance of the products formed during charging and is defined by ${ }^{21}$ :

$$
R_{f i l m}=\frac{\delta_{f i l m}(t)}{k_{f}}+R_{S E I}(t=0)
$$

and the rate at which the film thickness increases is calculated by:

$$
\frac{d \delta_{f i l m}}{d t}=\frac{-J_{s} M_{f}}{\rho_{f} F}
$$

In this work, a kinetic-limited mechanism for SEI growth ${ }^{21}$ is considered. The Butler-Volmer kinetic expression is used to predict the rates of the lithium ion deintercalation and intercalation reactions for each electrode:

$$
\begin{aligned}
\frac{J_{i}}{F}= & k_{i}\left(c_{i, \max }-x_{i, \text { surf }} c_{i, \max }\right)^{0.5}\left(x_{i, \text { surf }} c_{i, \max }\right)^{0.5} c_{e}^{0.5} \\
& \times\left[\exp \left(\frac{\alpha_{a, i} F}{R_{g} T} \eta_{i}\right)-\exp \left(\frac{-\alpha_{c, i} F}{R_{g} T} \eta_{i}\right)\right]
\end{aligned}
$$

The overpotentials for the lithium ion intercalation reaction for the

\begin{tabular}{|c|c|c|}
\hline Parameter & Value & Unit \\
\hline anode rate constant $\left(k_{n}\right)$ & $5.031 \mathrm{e}-11^{31}$ & $\mathrm{~m}^{2.5} / \mathrm{mol}^{0.5} / \mathrm{s}$ \\
\hline cathode rate constant $\left(k_{p}\right)$ & $2.344 \mathrm{e}-11^{31}$ & $\mathrm{~m}^{2.5} / \mathrm{mol}^{0.5} / \mathrm{s}$ \\
\hline anode radius particle $\left(R_{n}\right)$ & $2 e-6^{31}$ & $\mathrm{~m}$ \\
\hline cathode radius particle $\left(R_{p}\right)$ & $2 e-6^{31}$ & $\mathrm{~m}$ \\
\hline $\begin{array}{l}\text { anode solid phase diffusion coefficient of } \\
\qquad \mathrm{Li}^{+}\left(D_{s, n}\right)\end{array}$ & $1 e-14^{31}$ & $\mathrm{~m}^{2} / \mathrm{s}$ \\
\hline $\begin{array}{l}\text { cathode solid phase diffusion coefficient } \\
\qquad \text { of } \mathrm{Li}^{+}\left(D_{s, p}\right)\end{array}$ & $3.9 \mathrm{e}-14^{31}$ & $\mathrm{~m}^{2} / \mathrm{s}$ \\
\hline $\begin{array}{c}\text { anode maximum solid phase } \\
\text { concentration }\left(c_{n, \max }\right)\end{array}$ & $30555^{31}$ & $\mathrm{~mol} / \mathrm{m}^{3}$ \\
\hline $\begin{array}{l}\text { cathode maximum solid phase } \\
\text { concentration }\left(c_{p, \max }\right)\end{array}$ & $51555^{31}$ & $\mathrm{~mol} / \mathrm{m}^{3}$ \\
\hline cell resistance $\left(R_{\text {cell }}\right)$ & $0.02^{\mathrm{a}}$ & $\Omega$ \\
\hline cell capacity $(Q)$ & $1.65^{\mathrm{c}}$ & $\mathrm{Ah}$ \\
\hline initial anode loading $\left(l_{n}^{0}\right)$ & $5^{\mathrm{a}}$ & $\mathrm{g}$ \\
\hline initial cathode loading $\left(l_{p}^{0}\right)$ & $13^{\mathrm{a}}$ & $\mathrm{g}$ \\
\hline anode electroactive surface area $\left(S_{n}\right)$ & $3.41^{\mathrm{c}}$ & $\mathrm{m}^{2}$ \\
\hline cathode electroactive surface area $\left(S_{p}\right)$ & $3.86^{\mathrm{c}}$ & $\mathrm{m}^{2}$ \\
\hline anode initial state of charge & $0.9^{\mathrm{a}}$ & - \\
\hline cathode initial state of charge & $0.5^{\mathrm{a}}$ & - \\
\hline $\begin{array}{l}\text { anodic and cathodic transfer coefficient } \\
\qquad\left(\alpha_{a, i}\right)\end{array}$ & $0.5^{31}$ & - \\
\hline temperature $(T)$ & $298.15^{31}$ & $\mathrm{~K}$ \\
\hline gas constant $\left(R_{g}\right)$ & 8.3143 & $\mathrm{~J} / \mathrm{mol} / \mathrm{K}$ \\
\hline Faraday's constant $(F)$ & 96487 & $\mathrm{C} / \mathrm{mol}$ \\
\hline
\end{tabular}
anode and cathode are given as:

$$
\begin{aligned}
& \eta_{p}=\phi_{p}-U_{p}^{\theta} \\
& \eta_{n}=\phi_{n}-U_{n}^{\theta} \mp \frac{I_{a p p}}{S_{n}} R_{f i l m}\left(\left\{\begin{array}{l}
+ \text { charge } \\
- \text { discharge }
\end{array}\right\}\right)
\end{aligned}
$$

The open circuit potentials are empirical functions of the dimensionless surface concentrations $\left(x_{i, s u r f}\right)$ presented by Ramadass et al. ${ }^{21}$ :
Table I. Single particle model parameters ( ${ }^{\mathrm{a}}$ assumed, ${ }^{\mathrm{c}}{ }^{\text {calculated). }}$

number. In this study, the degradation electrode loading is expressed by the modified natural decay equation as follows:

$$
\frac{d \omega_{i}}{d t}=-\left(d f_{i, 1} e^{-t / t_{0}}+d f_{i, 2}\right) \quad i=p, n
$$

where $d f_{i, 1}$ and $d f_{i, 2}$ stand for the electrode degradation factors and $t_{0}$ stands for a characteristic time for the degradation. Eq. 11 is a simple empirical expression in order to give an example for the active material decay during the cycling. In section 4, we will then show how filtering methods are used to track the degradation loading obtained by the empirical expression. The parameters of SP model and the capacity fade are given in Table I and II respectively. Note that the capacity fade parameters are accelerated in order to make the model more nonlinear, indicative of a cell that fails early in life. The cell capacity is obtained by applying a low discharge current and calculating the integral of the current during the discharge until the voltage drops below the end of discharge voltage (EODV).

Degradation mechanisms. - The loss of Li ions studied in this work is due to the following reasons:

$$
\begin{aligned}
& U_{n}^{\theta}\left(x_{n, \text { surf }}\right)=.7222+.1387 x_{n, \text { surf }}+.029 x_{n, \text { surf }}^{0.5}-\frac{.0172}{x_{n, \text { surf }}}+\frac{.0019}{x_{n, \text { surf }}^{1.5}}+.2808 \mathrm{e}^{\left(0.9-15 x_{n, \text { surf }}\right)}-.7984 \mathrm{e}^{\left(0.4465 x_{n, \text { surf }}-0.4108\right)} \\
& U_{p}^{\theta}\left(x_{p, \text { surf }}\right)=\frac{-4.656+88.669 x_{p, \text { surf }}^{2}-401.119 x_{p, \text { surf }}^{4}+342.909 x_{p, \text { surf }}^{6}-462.471 x_{p, \text { surf }}^{8}+433.434 x_{p, \text { surf }}^{10}}{-1+18.933 x_{p, \text { surf }}^{2}-79.532 x_{p, \text { surf }}^{4}+37.311 x_{p, \text { surf }}^{6}-73.083 x_{p, \text { surf }}^{8}+95.96 x_{p, \text { surf }}^{10}}
\end{aligned}
$$

The cell voltage is obtained by the following equation:

$$
V_{\text {cell }}=\phi_{p}-\phi_{n}+I_{\text {app }} R_{\text {cell }}
$$

The degradation electrode loading defined in Eqs. 1a-2a was considered as volume fraction in ${ }^{22}$ and an empirical power law expression was used in order to correlate the parameter as a function of the cycle
1. occurrence of the side reaction on the negative electrode surface

2. loss of active material in the negative electrode

3. loss of active material in the positive electrode

The number of $\mathrm{Li}$ ion moles deintercalated from the cathode plus the number of ions lost due to loss of active material, and the number of Li ions intercalated into the anode minus the number of ions lost due to loss of active material during the charge, can be obtained by Eq. 12 . 


\section{Table II. Capacity fade parameters.}

\begin{tabular}{|c|c|c|}
\hline Parameter & Value & Unit \\
\hline $\begin{array}{l}\text { exchange current density for the film } \\
\text { formation reaction }\left(i_{0 f}\right)\end{array}$ & $1 e-6$ & $\mathrm{~A} / \mathrm{m}^{2}$ \\
\hline molecular weight of film $\left(M_{f}\right)$ & 101.95 & $\mathrm{~g} / \mathrm{mol}$ \\
\hline film specific conductivity $\left(k_{f}\right)$ & $1 e-5$ & $\mathrm{~S} / \mathrm{m}$ \\
\hline $\begin{array}{l}\text { open circuit potential for film } \\
\text { formation reaction }\left(U_{\text {reff }}\right)\end{array}$ & 0.38 & V \\
\hline $\begin{array}{l}\text { formation reaction }\left(U_{r e f f}\right) \\
\text { film density }\left(\rho_{f}\right)\end{array}$ & 2100 & $\mathrm{Kg} / \mathrm{m}^{3}$ \\
\hline $\begin{array}{l}\text { resistance of the Solid Electrolyte } \\
\text { Interphase layer }\left(R_{S E I}\right)\end{array}$ & $2 \mathrm{e}-6$ & $\Omega \mathrm{m}^{2}$ \\
\hline $\begin{array}{c}\text { characteristic time for } \\
\text { degradation }\left(t_{0}\right)\end{array}$ & $1 \mathrm{e} 6$ & $\mathrm{sec}$ \\
\hline anode degradation factor $\left(d f_{n, 1}\right)$ & $1 e-7$ & - \\
\hline anode degradation factor $\left(d f_{n, 2}\right)$ & $1 e-8$ & - \\
\hline cathodic degradation factor $\left(d f_{p, I}\right)$ & $5 e-8$ & - \\
\hline cathodic degradation factor $\left(d f_{p, 2}\right)$ & $5 e-9$ & - \\
\hline
\end{tabular}

Assuming the lost ions are part of the transferred ions, the calculated values by Eq. 12 can be considered as intercalated/deintercalated ions. In other words, exceeding the number of ions that deintercalate from the cathode over the number of intercalated ions into the anode (Eq. 12) implies that some of the deintercalated ions have been lost (no longer electrochemically active) and the remaining diffused into the electrode.

$$
\begin{aligned}
\Delta n_{L i^{+}, p}^{\text {charge }} & =\left(x_{p, a v g}^{0} \omega_{p}^{0}-x_{p, a v g}^{f} \omega_{p}^{f}\right) c_{p, \max } \frac{l_{p}^{0}}{\rho_{p}} \\
\Delta n_{L i^{+}, n}^{\text {charge }} & =\left(x_{n, \text { avg }}^{f} \omega_{n}^{f}-x_{n, \text { avg }}^{0} \omega_{n}^{0}\right) c_{n, \max } \frac{l_{n}^{0}}{\rho_{n}}
\end{aligned}
$$

where $x_{p, a v g}^{0}$ and $x_{p, a v g}^{f}$ are the dimensionless average concentration at the initial and final charge time (e.g. after $61 \mathrm{~min}$ for LEO) respectively. $l_{i}^{0}$ and $\rho_{i}$ represent the initial electrode loading and the active material density respectively. The same concept is used to calculate the number of $\mathrm{Li}$ ion moles intercalated into the cathode (minus the number of ions lost due to the loss of active material) and deintercalated from the anode (plus the number of ions lost due to the loss of active material) during the discharge:

$$
\begin{aligned}
\Delta n_{L i^{+}, p}^{\text {discharge }} & =\left(x_{p, a v g}^{f} \omega_{p}^{f}-x_{p, a v g}^{0} \omega_{p}^{0}\right) c_{p, \max } \frac{l_{p}^{0}}{\rho_{p}} \\
\Delta n_{L i^{+}, n}^{\text {discharge }} & =\left(x_{n, a v g}^{0} \omega_{n}^{0}-x_{n, a v g}^{f} \omega_{n}^{f}\right) c_{n, \max } \frac{l_{n}^{0}}{\rho_{n}}
\end{aligned}
$$

The total loss of $\mathrm{Li}$ ions is the difference between the number of $\mathrm{Li}$ ion moles intercalated into/deintercalated from the cathode and the moles deintercalated from/ intercalated into the anode:

$$
n_{\text {loss }}^{T}=\left|\Delta n_{L i^{+}, p}-\Delta n_{L i^{+}, n}\right|
$$

The loss of $\mathrm{Li}$ ions due to the side reaction can be determined by dividing the capacity loss to the Faraday's constant:

$$
n_{\text {loss }}^{\text {side }}=\frac{\int_{t_{0}^{\text {ch arge }}}^{t_{f}^{\text {ch arge }}} J_{s}(t) \omega_{n}(t) S_{n} d t}{F}
$$

The difference between the total loss of Li ions and the loss due to the side reaction ( $n_{\text {loss }}^{\text {side }}$ ) is the loss of Li ions due to the loss (passivation) of active material of the electrodes. Since only about $50 \%$ of the $\mathrm{Li}$ ions can be removed from $\mathrm{LiCoO}_{2}$ cathode, the maximum number of cyclable Li ion moles is obtained by Eq. 16. Initially there is $66.413 \mathrm{mmol} \mathrm{Li}$ ions inside the cathode.

$$
n_{T}^{c y c}(t)=\frac{0.5 l_{p}(t)}{M W_{\mathrm{LiCoO}_{2}}}
$$

Limiting electrode.- In order to determine the limiting electrode, the maximum capacity of both electrodes is required. For the graphite anode $\left(\mathrm{LiC}_{6}\right)$ the maximum charge for $\mathrm{C}_{6}$ is obtained as:

$$
q_{C_{6}}^{\max }=\frac{26.8\left(\frac{\mathrm{Ahr}}{\text { equivalent }}\right)}{72\left(\frac{\mathrm{gr}}{\text { equivalent }}\right)}=0.372\left(\frac{\mathrm{Ahr}}{\mathrm{gr}}\right)
$$

Because the initial anode loading is $5 \mathrm{~g}$, the maximum capacity of the anode is $1.86 \mathrm{Ahr}$. In a similar way, the cathode $\left(\mathrm{LiCoO}_{2}\right)$ maximum capacity can be calculated to be $3.562 \mathrm{Ahr}\left(0.274 \frac{\mathrm{Ahr}}{\mathrm{g}} * 13 g\right)$. However, since only about $50 \%$ of the $\mathrm{Li}^{+}$can be removed from $\mathrm{LiCoO}_{2}$, the capacity of the cathode is about $1.781 \mathrm{Ahr}$. As a result, the cell is cathode limited due to lower working capacity compared to the anode. In other words, the cell SOC can be estimated by the cathode SOC. Note that the limiting electrode can shift from the cathode to the anode during the cycling if the loss of active material rates of electrodes are different. Thus, it is required to verify the limiting electrode at each cycle.

LEO cycling. - The cell is cycled under LEO cycling conditions where the charge and discharge periods are constant due to constant orbit duration. LEO is used for satellites that are placed in Low Earth Orbit such as communication, telescopes, space-stations, etc. ${ }^{24}$ The initial SOC of the cathode and anode are 0.5 and 0.9 respectively corresponding to the cell voltage $4.12 \mathrm{~V}$ (completely charged). Then, the following steps are repeated until the cell dies (EODV $<3.0 \mathrm{~V})$ :

1. Constant current discharge $(1.03 \mathrm{C}$ rate, $60 \% \mathrm{DOD}$ for the first cycle) for $35 \mathrm{~min}$ discharge time. Unless the voltage drops below $3.0 \mathrm{~V}$ go to step 2.

2. Constant Current $(\mathrm{CC})$ charging $(1 \mathrm{C}$ rate) for $61 \mathrm{~min}$ charge time. If the voltage reaches the EOCV $(4.05 \mathrm{~V})$, go to step 3, if not go to step 1.

3. Constant Voltage $(\mathrm{CV})(4.05 \mathrm{~V})$ charging for the remaining charge time, go to step 1 .

Nonlinear dynamic system. - The system of differential algebraic equations (DAEs) for the nonlinear case can be written in the following general form:

$$
\left\{\begin{array}{l}
\dot{x}(t)=f(x(t), u(t), t)+w(t) \\
g(z(t), x(t), u(t), t)=0 \\
y(t)=h(x(t), t)+v(t)
\end{array}\right.
$$

where $x(t), z(t), y(t)$ and $u(\mathrm{t})$ are state, algebraic, output and input variables respectively. The nonlinear functions $f, g$ and $h$ are assumed to be continuously differentiable and $w(t)$ and $v(t)$ are zero-mean Gaussian white-noise for the process and measurement variables respectively. The detail expressions for the functions $f, g$ and $h$ in terms of the model equations for three different LEO steps are presented in Appendix B. The covariances are given by:

$$
\left\{\begin{array}{l}
E\left[w(t) w^{T}(\tau)\right]=Q \delta(t-\tau) \\
E\left[v(t) v^{T}(\tau)\right]=R \delta(t-\tau) \\
E\left[v(t) w^{T}(\tau)\right]=0
\end{array}\right.
$$

where $\delta(t)$ is Dirac function and $Q$ and $R$ are the process and measurement covariance matrices respectively. The state variables are the SOC $\left(x_{i, \text { avg }}\right.$ in Eqs. $\left.1-2\right)$ and the degradation $\left(\omega_{i}\right.$ in Eq. 11$)$ of the electrodes:

$$
x(t)=\left[x_{p, a v g}, x_{n, a v g}, \omega_{p}, \omega_{n}\right]
$$


The state Eqs. 1a-2a can be written as follows for the electrodes' SOC:

$$
\frac{d x_{i, a v g}}{d t}=\frac{-15 D_{s, i}}{R_{i}^{2}}\left(x_{i, a v g}-x_{i, \text { surf }}\right)+q_{j}, \quad i=p, n \quad j=1,2
$$

where $q_{j}$ is a process noise (first and second diagonals of Matrix $Q$ ). In order to show the capability of the proposed approach, the following equation is used to predict the degradation of the electrodes by means of filtering methods:

$$
\frac{d \omega_{i}}{d t}=q_{j}, \quad i=p, n j=3,4
$$

where $q_{j}$ are the third and forth diagonals of Matrix $Q$. Thus, Eq. 11 given the parameters in Table II is first used to generate the synthetic data and then the filtering methods apply Eq. 19 to reproduce the data that can be considered for the estimation of the correct parameters of Eq. 11 .

\section{Application of Kalman Filtering to Nonlinear Dynamic Systems}

Kalman Filter (KF) is used to estimate the states of a linear dynamic system perturbed by Gaussian noise by means of minimization of the mean squared error between the model predictions and the measurements that are linear functions of the system states and include additive Gaussian noise. ${ }^{25}$ However, the majority of battery models including empirical and physics-based rely on nonlinear systems which confines the use of the KF method.

Two different filtering methods are used for nonlinear systems including Extended Kalman Filtering (EKF) and Sigma-Point Kalman Filtering (SPKF). ${ }^{26}$ In the former the nonlinear system is linearized while the latter calculates approximations of the optimal terms of the Gaussian probability distribution function (pdf). The SPKF family contains all Kalman filters which are based on a deterministic sampling technique called the sigma-point approach. ${ }^{26}$ Unscented Kalman Filtering (UKF) and Central difference Kalman Filtering (CDKF) are two examples of the SPKF family. The only difference between the two approaches is in their weighting constants. ${ }^{26}$ It this study, the EKF method is compared to the UKF as a candidate of the SPKF family due to the popularity of UKF.

Extended Kalman Filtering (EKF).- Extended Kalman Filtering (EKF) was the first successful application of the KF to nonlinear systems and it is still commonly used. ${ }^{25}$ In EKF, the nonlinear system is linearly approximated using the Taylor series around the operating point at each time step. Thus, the success of EKF strongly depends on the degree of nonlinearity of the dynamic system and the states might diverge over time due to errors caused by the linearization. The following steps present the EKF algorithm (more thorough description of EKF can be found $\mathrm{in}^{27}$ ):

- Specify the initial mean and covariance of the state variables, $k=0$ :

$$
\begin{aligned}
& \hat{x}_{0}=E\left[x_{0}\right], \\
& P_{0}^{x}=E\left[\left(x_{0}-\hat{x}_{0}\right)\left(x_{0}-\hat{x}_{0}\right)^{T}\right]
\end{aligned}
$$

- Estimate the covariance for the process noise $(Q)$ and the measurement noise $(R)$ based on prior knowledge of the system.

- For $k=0,1, \ldots, \infty$ :

1. Compute the Jacobian of the measurement function:

$$
H_{k}\left(\hat{x}_{k}^{-}\right)=\left.\frac{\partial h}{\partial x}\right|_{\hat{x}_{k}^{-}}
$$

Because there is no explicit solution for the measurement (voltage during $\mathrm{CC}$ charge and discharge and current during $\mathrm{CV}$ charging) due to occurrence of the side reaction and loss of active materials, backward finite difference method was used to approximate the Jacobian.

2. Calculate the filter gain:

$$
K_{k}=P_{k}^{x-} H_{k}^{T}\left(\hat{x}_{k}^{-}\right)\left[H_{k}\left(\hat{x}_{k}^{-}\right) P_{k}^{x-} H_{k}^{T}\left(\hat{x}_{k}^{-}\right)+R_{k}\right]^{-1}
$$

3. Update the states and the covariance:

$$
\begin{aligned}
& x_{k}=\hat{x}_{k}^{-}+K_{k}\left[y_{k}^{*}-h\left(\hat{x}_{k}^{-}\right)\right] \\
& P_{k}^{x}=\left[I-K_{k} H_{k}\left(\hat{x}_{k}^{-}\right)\right] P_{k}^{x-}
\end{aligned}
$$

4. Project the states which are outside the feasible region to the feasible region boundary which is [ $\left[\begin{array}{ll}0 & 1\end{array}\right]$ for the dimensionless average concentrations and the degradations.

5. Compute the Jacobian of the process model:

$$
J_{k}\left(\hat{x}_{k}^{-}\right)=\left.\frac{\partial f}{\partial x}\right|_{\hat{x}_{k}^{-}}
$$

If we consider Eq. 18-19 as the state equations, the following invariant Jacobian matrix is obtained:

$$
J=\operatorname{diag}\left(\left[\frac{-15 D_{s, p}}{R_{p}^{2}}, \frac{-15 D_{s, n}}{R_{n}^{2}}, 0,0\right]\right)
$$

6. Propagate the state:

$$
\left\{\begin{array}{l}
\hat{x}_{k+1}^{-}=\int_{t_{k}}^{t_{k+1}} f(x(t), u(t), t) d t \\
\text { s.t. } \quad g(x(t), u(t), t)=0
\end{array}\right.
$$

7. Propagate the covariance:

$$
\left\{\begin{array}{l}
\Phi=e^{J_{k}\left(\hat{x}_{k}^{-}\right) \Delta t} \\
P_{k+1}^{x-}=\Phi P_{k}^{x} \Phi^{T}+Q
\end{array}\right.
$$

\section{- End For loop}

Unscented Kalman Filtering $(U K F)$.- Due to use of linearization, the EKF method has the limitation for highly nonlinear systems. In order to overcome the EKF difficulties, the UKF approach has been developed based on the fact that the approximation of a pdf is more accurate than the approximation of an arbitrary nonlinear function. The UKF, first proposed by Julier et al., ${ }^{28}$ is a derivative free filtering method that approximates the pdf of the measurement variable given the pdf of the state variables through nonlinear transformation. First, the state distribution is assumed to have the Gaussian pdf with the approximated mean and covariance. Then, a set of sigma points that represents the pdf with the same mean and covariance are carefully chosen. Each of the sigma points are then propagated through the true nonlinear system and the posterior mean and covariance of the measurement variable in the case of being Gaussian are calculated. The UKF is more accurate with respect to the EKF method while the order of calculations is the same as linearization. The main steps of the nonadaptive covariance UKF are as follows (more thorough description of UKF can be found in ${ }^{29}$ ): $k=0$

- Specify the initial mean and covariance for the state variables,

$$
\begin{aligned}
& \hat{x}_{0}=E\left[x_{0}\right], \\
& P_{0}^{x}=E\left[\left(x_{0}-\hat{x}_{0}\right)\left(x_{0}-\hat{x}_{0}\right)^{T}\right]
\end{aligned}
$$

- Estimate the covariance for the process noise $(Q)$ and the measurement noise $(R)$ based on prior knowledge of the system.

- For $k=1,2, \ldots, \infty$ :

1. Generate $(2 N+1)$ sigma points based on the present state covariance by using a Cholesky factorization of the covariance matrix as follows, where $N$ is the number of the 
state variables:

$$
X_{i, k-1}= \begin{cases}\hat{x}_{k-1}, \quad i=0 \\ \hat{x}_{k-1}+\gamma^{*} \operatorname{chol}\left(P_{k-1}^{x}\right), \quad i=1, \ldots, N \\ \hat{x}_{k-1}-\gamma^{*} \operatorname{chol}\left(P_{k-1}^{x}\right), \quad i=N+1, \ldots, 2 N\end{cases}
$$

where $\gamma$ is a scaling parameter given by:

$$
\gamma=\sqrt{N+\lambda}, \quad \lambda=\alpha^{2}(N+\kappa)-N,
$$

where $\alpha(0 \leq \alpha \leq 1)$ and $\kappa(\kappa \geq 0)$, tuning parameters, control the semi-positive definiteness of the covariance matrix and the size of the sigma points distribution respectively.

2. Project the sigma points which are outside the feasible region to the feasible region boundary which is $[0$ 1] for the dimensionless average concentrations and the degradations.

3. Update the sigma points at the next time step by integrating the DAEs up to the next time at each point:

$$
\left\{\begin{array}{l}
X_{i, k}=\int_{t_{k-1}}^{t_{k}} f\left(X_{i}(t), u(t), t\right) d t \\
\text { s.t. } \quad g\left(X_{i}(t), u(t), t\right)=0
\end{array} \quad i=0,1, \ldots, 2 N\right.
$$

4. Update the measured variable (voltage for CC charge and discharge, current for $\mathrm{CV}$ charge) by transforming the sigma points through the measurement update function:

$$
Y_{i, k}=h\left(X_{i, k}, u_{k}\right), \quad i=0,1, \ldots, 2 N
$$

5. Calculate the prior state and measurement estimate and the covariances:

$$
\begin{gathered}
\left\{\begin{array}{l}
\hat{x}_{k}^{-}=\sum_{i=0}^{2 N} W_{M}^{i} X_{i, k} \\
\hat{y}_{k}^{-}=\sum_{i=0}^{2 N} W_{M}^{i} Y_{i, k}
\end{array}\right. \\
\left\{\begin{array}{l}
P_{k}^{x-}=\sum_{i=0}^{2 N} W_{C}^{i}\left(X_{i, k}-\hat{x}_{k}^{-}\right)\left(X_{i, k}-\hat{x}_{k}^{-}\right)^{T}+Q \\
P_{k}^{y}=\sum_{i=0}^{2 N} W_{C}^{i}\left(Y_{i, k}-\hat{y}_{k}^{-}\right)\left(Y_{i, k}-\hat{y}_{k}^{-}\right)^{T}+R \\
P_{k}^{x y}=\sum_{i=0}^{2 N} W_{C}^{i}\left(X_{i, k}-\hat{x}_{k}^{-}\right)\left(Y_{i, k}-\hat{y}_{k}^{-}\right)^{T}
\end{array}\right.
\end{gathered}
$$

The weights $W_{M}^{i}$ and $W_{C}^{i}$ are given by:

$$
\left\{\begin{array}{l}
W_{M}^{0}=\frac{\lambda}{N+\lambda}, \quad i=0 \\
W_{C}^{0}=\frac{\lambda}{N+\lambda}+\left(1-\alpha^{2}+\beta\right), \quad i=0 \\
W_{M}^{i}=W_{C}^{i}=\frac{1}{2(N+\lambda)}, \quad i=1, \ldots, 2 N
\end{array}\right.
$$

where $\beta$ is a non negative weighting parameter which affects the covariance weight for the zeroth sigma point.

6. Calculate the filter gain:

$$
K_{k}=P_{k}^{x y}\left(P_{k}^{y}\right)^{-1}
$$

7. Correct the state estimate and covariance based on the difference between the predicted and measured values $\left(y_{k}^{*}\right)$ :

$$
\left\{\begin{array}{l}
\hat{x}_{k}=\hat{x}_{k}^{-}+K_{k}\left(y_{k}^{*}-\hat{y}_{k}^{-}\right) \\
P_{k}^{x}=P_{k}^{x-}-K_{k} P_{k}^{y} K_{k}^{T}
\end{array}\right.
$$

- End For loop

In order to improve the UKF prediction at the initial time of each LEO step, we tried to update the states initially using the first measurement in a similar way that we performed in the EKF approach (i.e. the states are first updated and then propagated). In other words, steps 3, 7 and 9 are performed initially and then the aforementioned procedure is repeated for other time steps. This reduces the UKF error of the state variables at the initial time and also the UKF converges to the true value rapidly.

\section{Results and Discussion}

To compare the EKF and the UKF approaches the results for the first cycle are discussed and then three different capacity loss cases are studied during the cell life. The synthetic data was generated by adding zero mean Gaussian noise with a specified standard deviation ( $0.0025 \mathrm{~V}$ for the voltage and $0.005 \mathrm{~A}$ for the current) to the chargedischarge curves obtained from the SP model using Eqs. 1-11 and the parameters of Tables I and II. Fig. 1 shows the synthetic data for the first three cycles when there is no capacity loss. In order to predict the data, nonlinear filtering methods by means of the SP model with the same parameters are used. However, Eq. 11 is replaced by Eq. 19 for the electrodes' degradations with the purpose of demonstrating the performance of the current approach. The initial SOC for both electrodes are assumed $10 \%$ off to the true values and data is obtained every ten seconds. The lower and upper bounds for the state variables are 0.001 and 1.0 respectively.

First cycle.- Among different combinations for the initial covariances and the process noises, the following matrices resulted in the minimum residuals between the filtering outputs and the true values:

$$
\begin{array}{r}
E K F\left\{\begin{array}{l}
P_{0}^{x}=\operatorname{diag}\left(\left[10^{-2} 10^{-2} 10^{-10} 10^{-10}\right]\right) \\
Q=\operatorname{diag}\left(\left[10^{-8} 10^{-8} 10^{-10} 10^{-10}\right]\right)
\end{array}\right. \\
\operatorname{UKF}\left\{\begin{array}{l}
P_{0}^{x}=\operatorname{diag}\left(\left[10^{-2} 10^{-2} 10^{-10} 10^{-10}\right]\right) \\
Q=\operatorname{diag}\left(\left[10^{-16} 10^{-16} 10^{-8} 10^{-8}\right]\right)
\end{array}\right.
\end{array}
$$

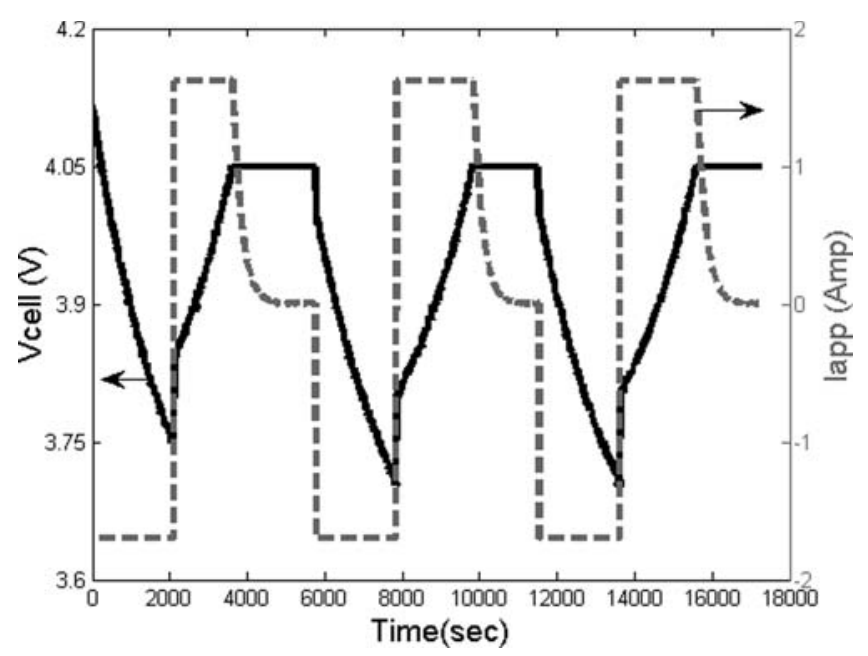

Figure 1. Cell voltage and applied current for the first three cycles (no capacity fade). 


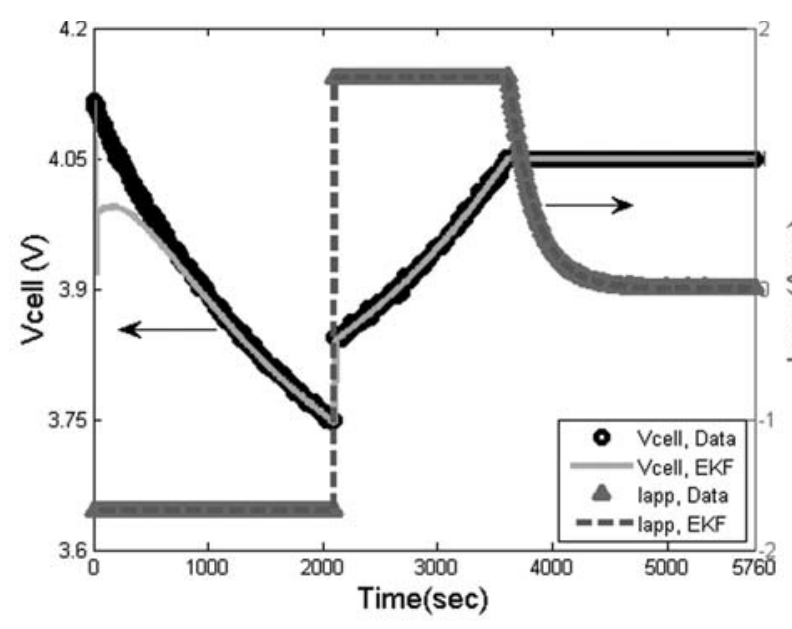

(a)

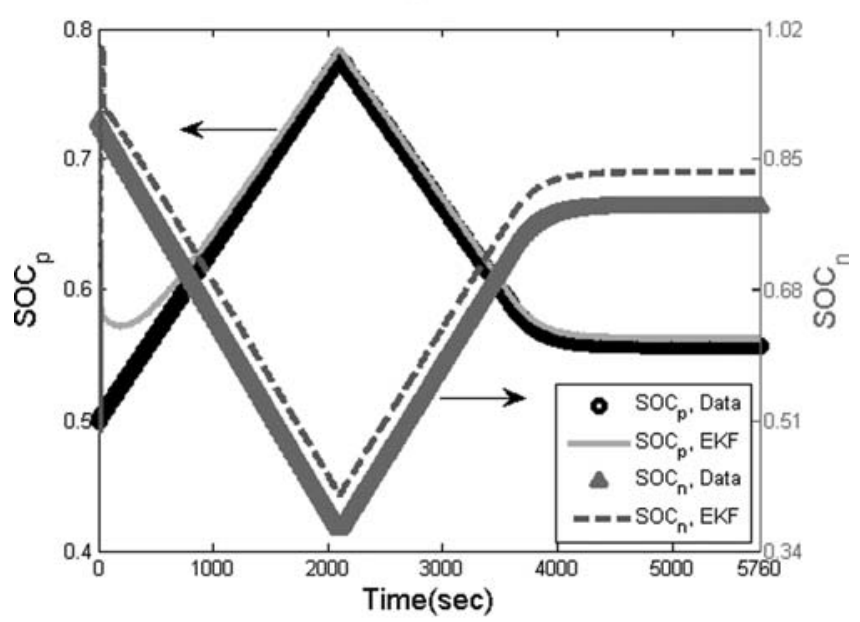

(b)

Figure 2. EKF prediction of the synthetic data for the first cycle (a) cell voltage and applied current (b) SOC of the positive and the negative electrodes.

The measurement noises used for both filtering methods and the UKF parameters are given by:

$$
\begin{aligned}
& R_{V}=0.0025^{2}, R_{I}=0.005^{2} \\
& \alpha=0.5, \quad \beta=2, \quad \kappa=0
\end{aligned}
$$

where $R_{V}$ and $R_{I}$ are the measurement noise for the voltage and the current, respectively. Figs. 2 and 3 show the EKF and the UKF results for the first cycle including $35 \mathrm{~min}$ discharge and $61 \mathrm{~min}$ charge respectively. The figures indicate that the UKF deviation from the data is much less than the EKF particularly in the voltage and the anode SOC.

Cell life.- Three combinations of different capacity loss mechanisms during the cell life are selected to study the loss of cyclable $\mathrm{Li}$ ions and the end of discharge voltage (EODV) drop and also in order to compare the filtering methods for the SOC and the loss of active material prediction. In all cases the side reaction near the anode surface occurs while the anode loss of active material happens in the second and the third cases and the cathode loss of active material only takes place in the third case.

Case study 1: anode side reaction.-The occurrence of the solvent reduction near the negative electrode surface is the only reason for the capacity loss and there is no loss of active materials in the electrodes for this case. Thus, the electrodes' degradations are equal to one during cycling. The first cycle starts with the constant current discharge from

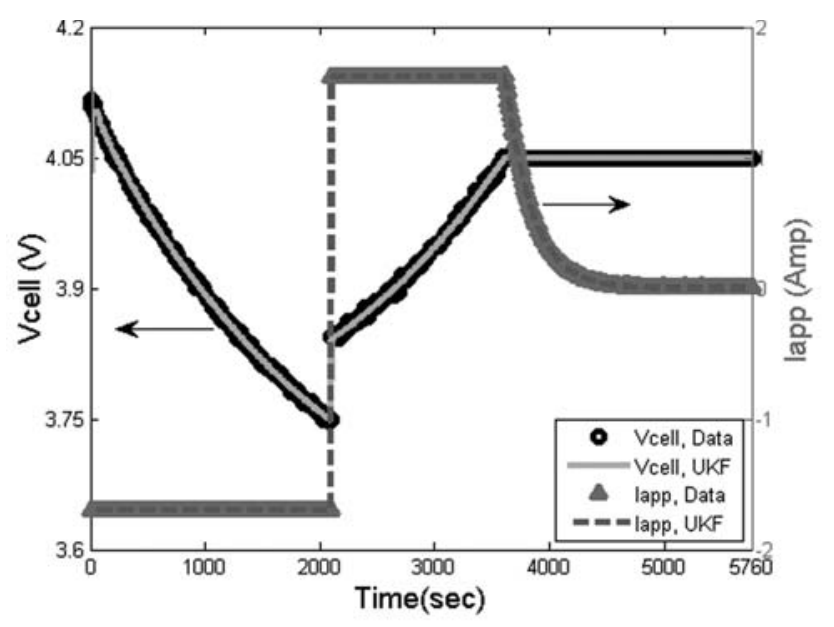

(a)

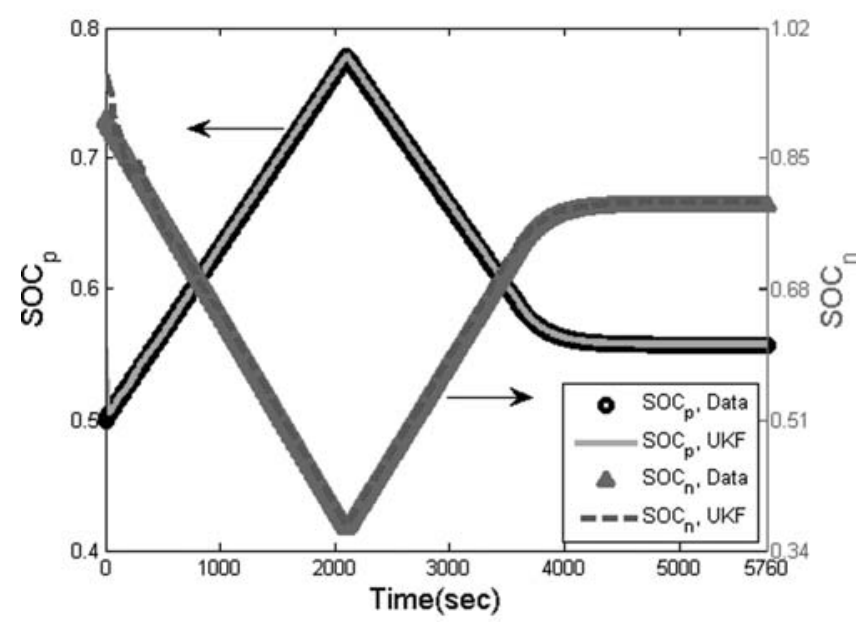

(b)

Figure 3. UKF prediction of the synthetic data for the first cycle (a) cell voltage and applied current (b) SOC of the positive and the negative electrodes.

the initially fully charged cell where $36.938 \mathrm{mmol} \mathrm{Li}$ ions transferred between the electrodes and the voltage drops to 3.747 . Then, the cell is charged to the end of the charge voltage (EOCV) where only 29.306 mmol Li ions deintercalated from the cathode and $29.272 \mathrm{mmol}$ of the ions intercalated into the anode $(0.034 \mathrm{mmol}$ of the ions are consumed in the side reaction). Because the number of ions transferred from the cathode to the anode during the first charge is greatly less than the number of ions during the discharge, a considerable drop in the anode SOC and a substantial increase in the cathode SOC results at the end of charge and consequently at the end of discharge. Hence, the cathode OCP decreases, but the anode OCP increases. However, the cathode OCP decreases faster than the anode OCP increases, leading to a net EODV decrease (3.702) as shown in Fig. 4. As a result the CC charge time of the second cycle increases and thereby the number of ions deintercalated from the cathode and intercalated into the anode rises to 36.942 and $36.911 \mathrm{mmol}$ respectively. However, during the discharge the number of $\mathrm{Li}$ ion moles deintercalated from the anode $(36.938 \mathrm{mmol})$ is the same as the number of moles intercalated into the cathode and remained constant during the cell life (Fig. 5, dasheddot line), because the time and current are fixed and there is no side reaction and loss of active materials. Thus, the number of ions leaving both electrodes is greater than the number of ions that diffuse into them and consequently the SOC of both electrodes at the end of charge and discharge decreases, causing an additional drop in EODV and an increase in the $\mathrm{CC}$ charge time. Therefore, during the remaining cycles the number of ions that deintercalate from both electrodes is 


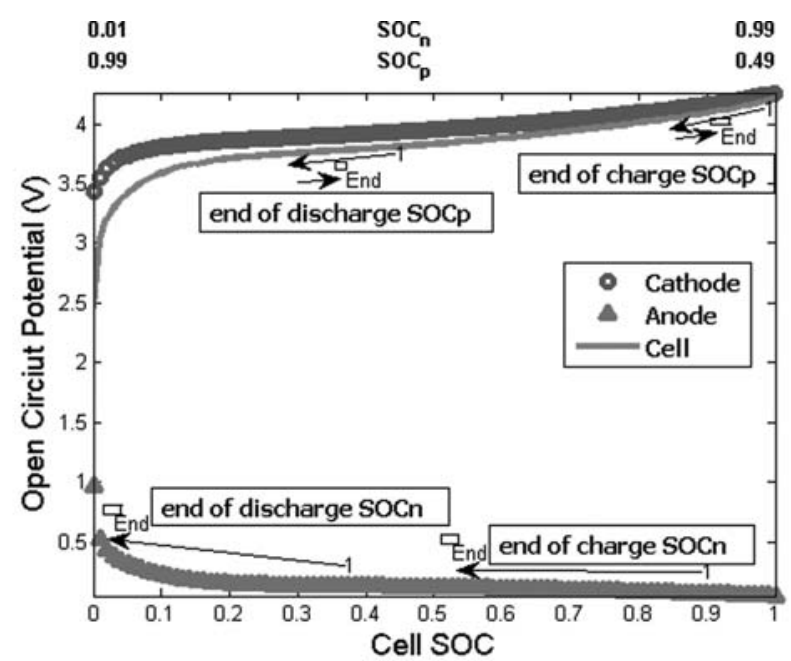

(a)

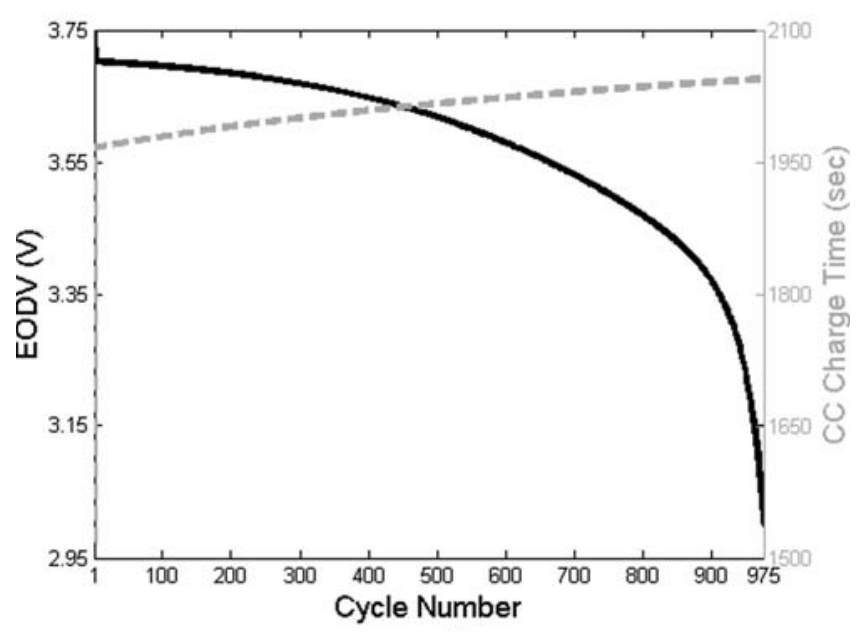

(b)

Figure 4. (a) variation of the initial charge and discharge SOC and OCP for each electrode during the cell life ("1" and "End" stand for the first and the last cycles respectively), (b) EODV and CC charge time versus cycle number.

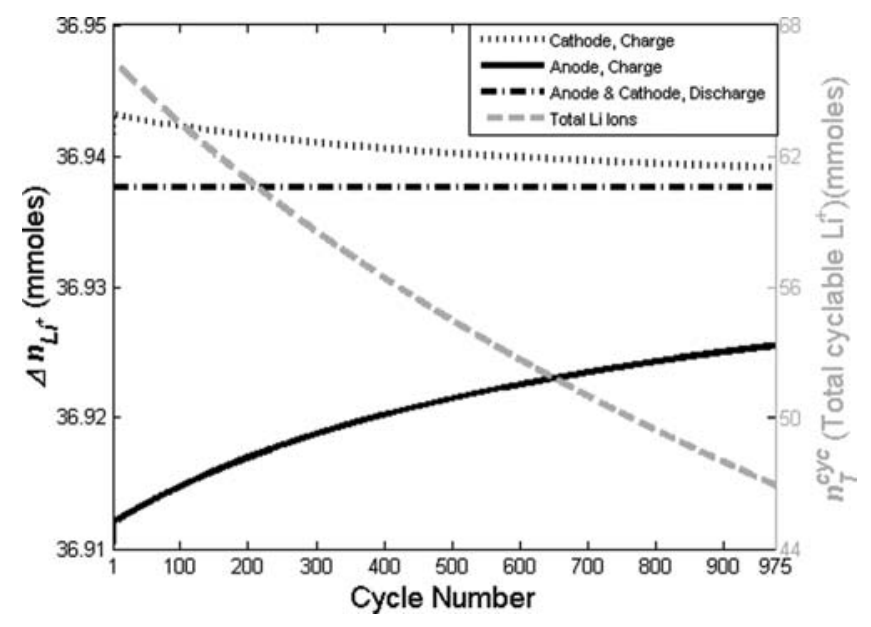

Figure 5. Case study 1, Number of Li ions deintercalated from/intercalated into the cathode/anode during charge/discharge and total cyclable Li ions during the cell life.

more than the number of ions going into electrodes and as a result the SOC of the both electrodes at the beginning of the charge and discharge cycle decreases from the second cycle until the cell dies as shown in Fig. 4a. However, the SOC reduction of the anode is more than the cathode SOC due to occurrence of the side reaction on the anode surface. The decrease in electrodes' SOCs at the end of discharge leads the EODV to drop and the CC charge time to rise during the remaining cycles (Fig. 4b). In the first case study the cell dies after 975 cycles where the EODV drops below 3.0 V. Table III contains the initial SOCs of the electrodes, EODV and the CC charge time for cycles 1,2 and 500.

The number of $\mathrm{Li}$ ions deintercalated from/intercalated into the cathode and the number of $\mathrm{Li}$ ions intercalated into/deintercalated from the anode during the charge/discharge calculated using Eq. 12/ Eq. 13 between the second and the last cycles, together with the total number of cyclable Li ions during the cell life obtained by Eq. 16 are depicted in Fig. 5. The difference between the numbers of Li ion moles at each cycle is due to the side reaction of Li ions with the solvent near the anode surface that causes the total number of cyclable Li ions decrease during cycling (dashed line). Fig. 5 also shows that the number of ions diffusing into the anode during the charge increases with the cycle number (solid line) due to the side reaction rate reduction as well as the increase in CC charge time. Nevertheless, the number of ions that departs the cathode during the charge drops between the third

Table III. Comparison of the initial electrodes' SOC, EODV and the CC charge time of three case studies for different cycles.

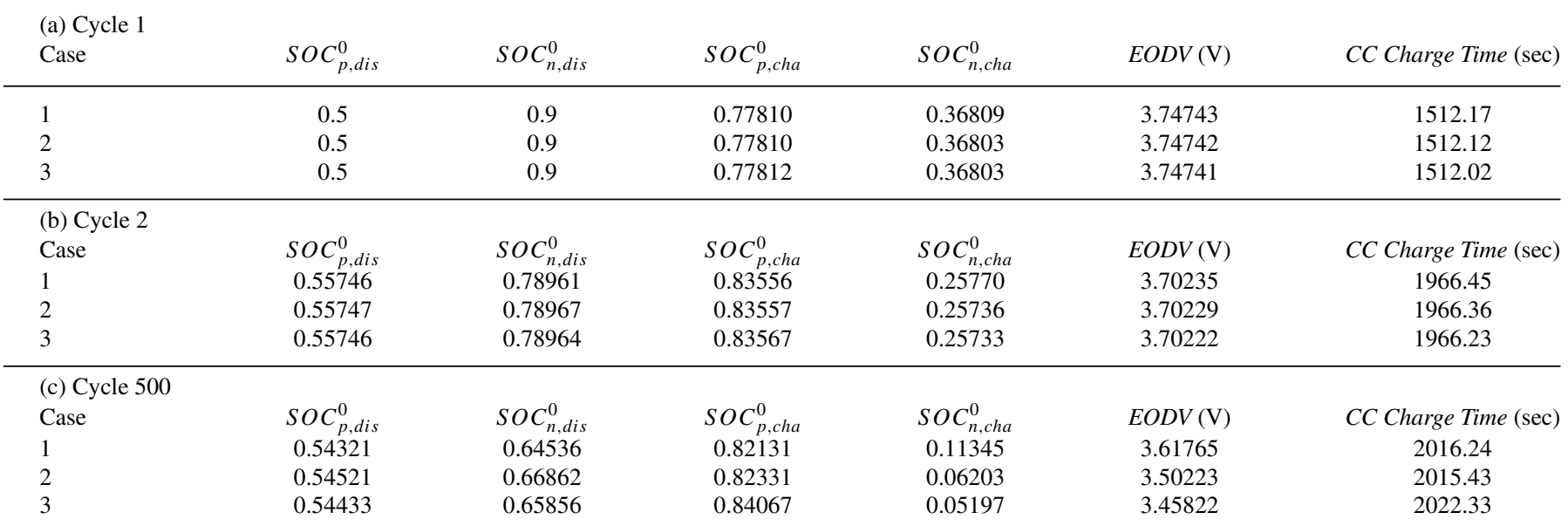




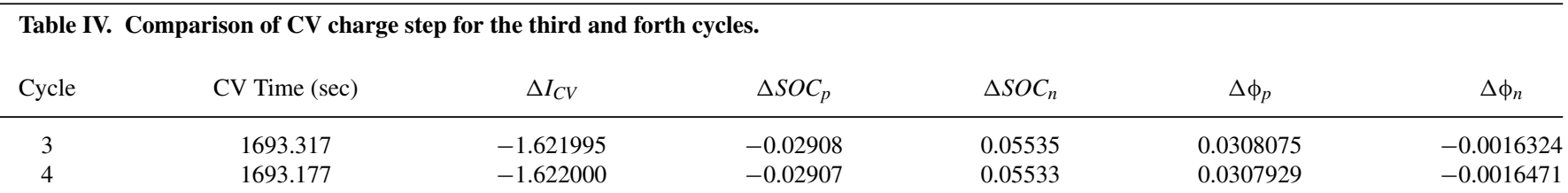

and the last cycles (dotted line), because of the decrease in number of the deintercalated ions during the $\mathrm{CV}$ charge caused by two following reasons. First, the $\mathrm{CV}$ charge time decreases due to fixed total charge time (61 $\mathrm{min}$ ) and second the drop in the $\mathrm{CV}$ current becomes more as the cycle number increases. Table IV compares the CV charge time, the current drop and the variations of SOCs and potentials of both electrodes during the CV charge for the third and forth cycles. During the CV charge the current is obtained using Eq. 10:

$$
I_{C V}=\frac{V_{\text {cell }}-\phi_{p}+\phi_{n}}{R_{\text {cell }}}
$$

The current change can be obtained by taking the difference of Eq. 20 and using Eq. 8 ( $V_{\text {cell }}$ is constant):

$$
\Delta I_{C V}=\frac{-\Delta \phi_{p}+\Delta \phi_{n}}{R_{\text {cell }}}
$$

Because the active surface area of the anode is less than the cathode's surface area (Table I), the anode SOC increase $\left(2 \mathrm{e}^{-5}\right)$ is greater than the cathode SOC drop $\left(10^{-5}\right)$. Consequently, the anode potential change $\left(1.47 \mathrm{e}^{-5} \mathrm{~V}\right)$ becomes more than the cathode potential change $\left(1.46 \mathrm{e}^{-5} \mathrm{~V}\right)$ according to Eq. 8, even though the slope of cathode OCP at this point is more than the anode OCP slope. Thus, the current drops more in forth cycle with respect to third cycle based on Eq. 21. The aforementioned reasons require that the number of deintercalated ions from the cathode during the CV charge reduce as the cell is cycled. This reduction is more than the increase in the number deintercalated ions during the $\mathrm{CC}$ charge causing a drop in the number of ions leaving the cathode during the total charge time. In order to check the consistency of the $\mathrm{Li}$ ion mole balance equations the total loss of active material (Eq. 14) and the loss of $\mathrm{Li}$ ions due to the side reaction (Eq. 15) were calculated at each cycle. The equality of both quantities at each cycle indicated that the side reaction was the only reason for the loss of Li ions during the cell life.

At the next step the EKF and the UKF methods are used to estimate the SOC and degradation of both electrodes by means of the SP model and the voltage-current synthetic data. Fig. 6 compares the cell voltage errors and the electrodes' degradations of two filtering methods indicating the superiority of the UKF approach in prediction of the data. Fig. $6 \mathrm{~b}$ verifies that the UKF is able to predict the true values of the electrodes' degradations (i.e. $\left.\omega_{p}(t)=\omega_{n}(t)=1\right)$ during the cycling. Hence, the UKF identifies the fade mechanism as there is no loss of active material inside both electrodes. The residuals and the computation time of both methods are also given in Table V. The UKF took about $1.7 \mathrm{sec}$ per cycle longer than the EKF for the estimation, yet UKF produced more accurate results for all variables when compared to EKF. Note that the maximum error of the anode SOC (the first twenty data points are excluded due to initial deviation of the SOCs) is about 0.023 while the maximum error in the cathode SOC (cell SOC) is less than 0.002. This occurs at the initial time of a new LEO step due to a considerable alteration in the states and measurements while the state covariance matrix at the previous time on a different step was used. The average values of the SOCs errors verify that the UKF was able to estimate the states for the remaining times successfully.

Case study 2: anode side reaction and loss of active material.-In this case the anode degradation is decreasing by Eq. 11 given the parameters in Table II while the cathode degradation is kept constant at one during the cycling (i.e. $\left.\omega_{p}(t)=1\right)$. Fig. 7a represents the number of $\mathrm{Li}$ ions deintercalated from /intercalated into the electrodes during charge and discharge as a function of cycle number. The results in Fig. $7 \mathrm{a}$ indicate that the number of ions during the charge changes the same way as in the first case study. However, the number of ions that deintercalate from the anode during the discharge is greater than the number of ions that intercalate into the cathode due to the anode loss of active material. Therefore, the SOC of the anode at the end of discharge decreases more rapidly than the first case study, causing the EODV drop below $3.0 \mathrm{~V}$ after only 667 cycles (Fig. 7b). Nevertheless, the changes in other SOCs (cathode at the end of discharge and both electrodes at the end of charge) are less than the first case (Table III). Because the cell voltage reaches to EOCV quicker with respect to case 1 due to the anode current density increase, the amount of time

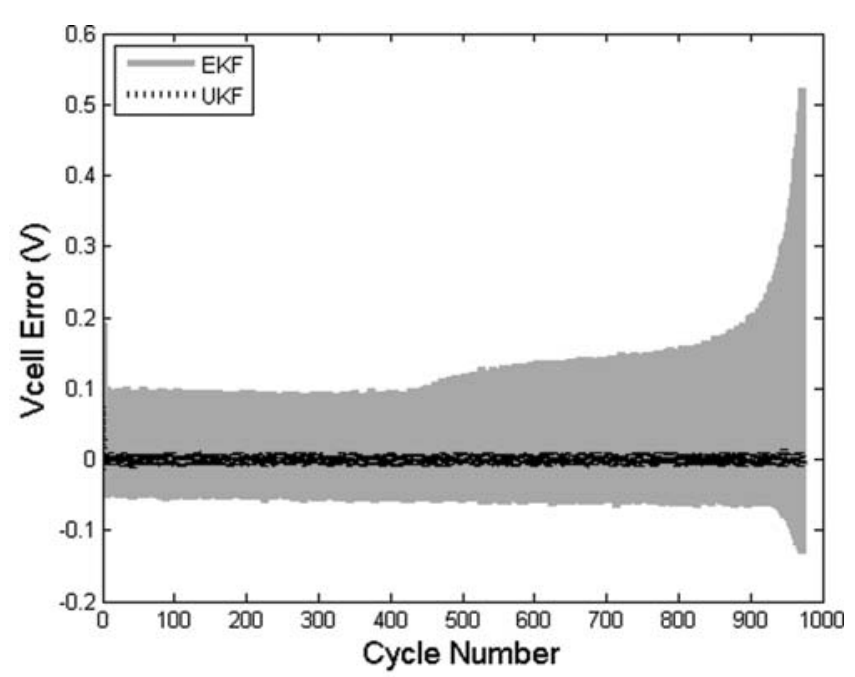

(a)

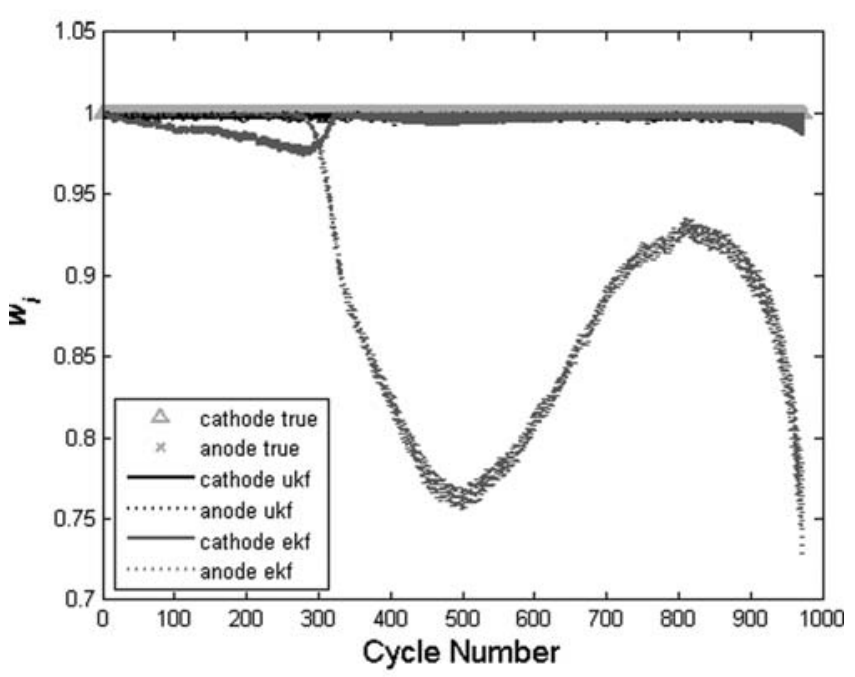

(b)

Figure 6. Case study 1, EKF and UKF comparison (a) cell voltage errors between the filtering and the synthetic data (b) degradations of the electrodes predicted by filtering and the synthetic data. 
Table V. Comparison of the EKF and the UKF results for three case studies (The first 20 data points were not considered to obtain the maximum of the voltage and the SOCs).

(a) Measurements errors and computation time

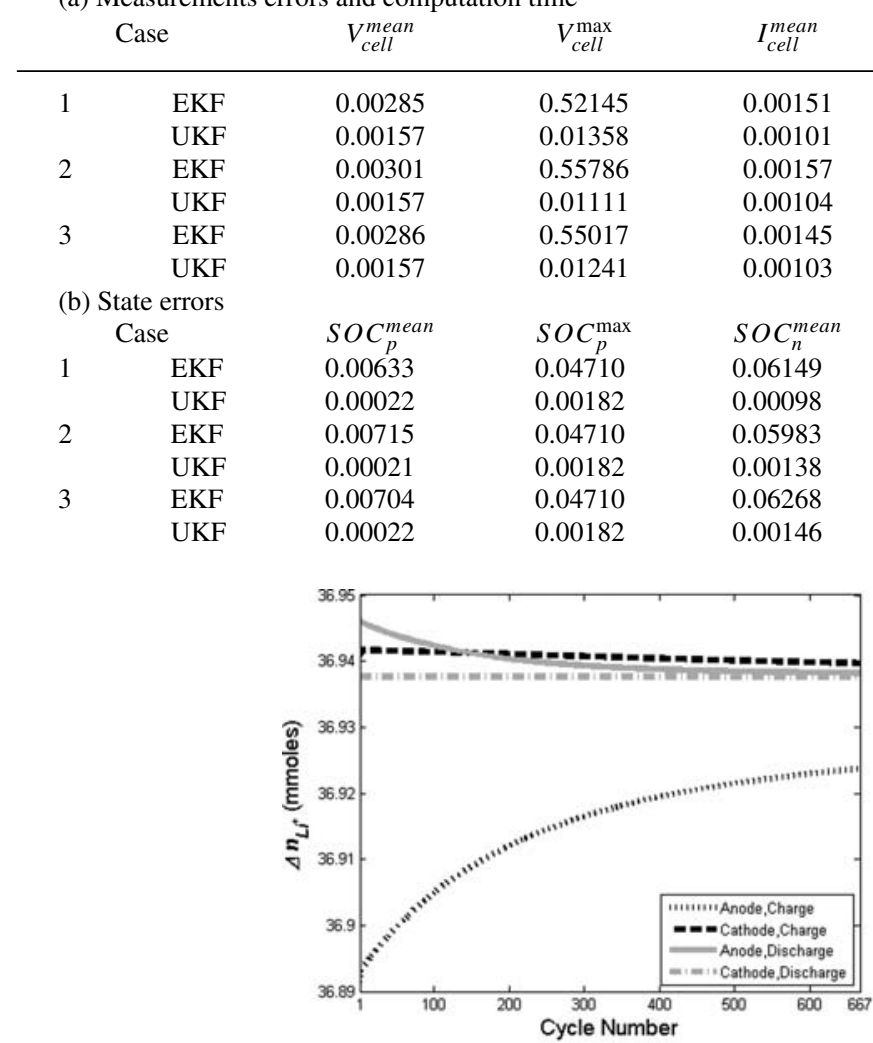

(a)

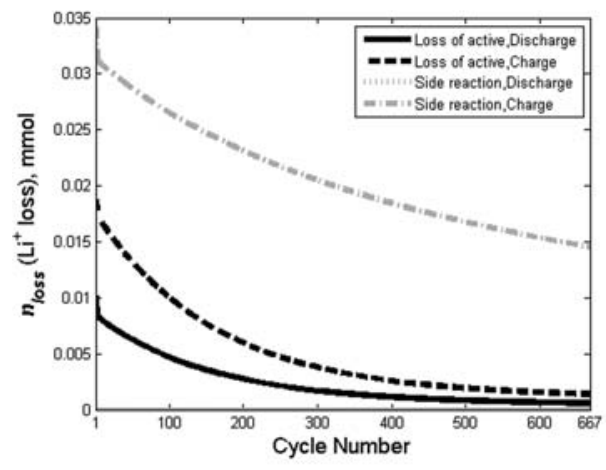

(c)

$\begin{array}{cc}I_{\text {cell }}^{\max } & \frac{\text { CPUTime(min) }}{96 \text { mincycle }} \\ 0.25101 & 1.963 \\ 0.04402 & 2.255 \\ 0.28700 & 1.278 \\ 0.03406 & 1.519 \\ 0.14692 & 1.190 \\ 0.03110 & 1.160\end{array}$

$\begin{array}{lllll}\operatorname{SOC}_{n}^{\max } & \omega_{p}^{\text {mean }} & \omega_{p}^{\max } & \omega_{n}^{\text {mean }} & \omega_{n}^{\max } \\ 0.1755 & 0.0056 & 0.0259 & 0.0989 & 0.2713 \\ 0.0228 & 0.0015 & 0.0053 & 0.0027 & 0.0076 \\ 0.1716 & 0.0133 & 0.0556 & 0.0968 & 0.2373 \\ 0.0228 & 0.0022 & 0.0070 & 0.0030 & 0.0129 \\ 0.1840 & 0.0373 & 0.0665 & 0.1089 & 0.2382 \\ 0.0228 & 0.0017 & 0.0065 & 0.0027 & 0.0130\end{array}$

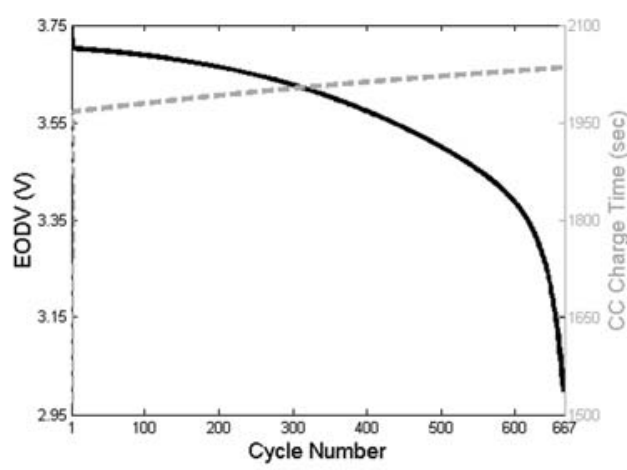

(b)

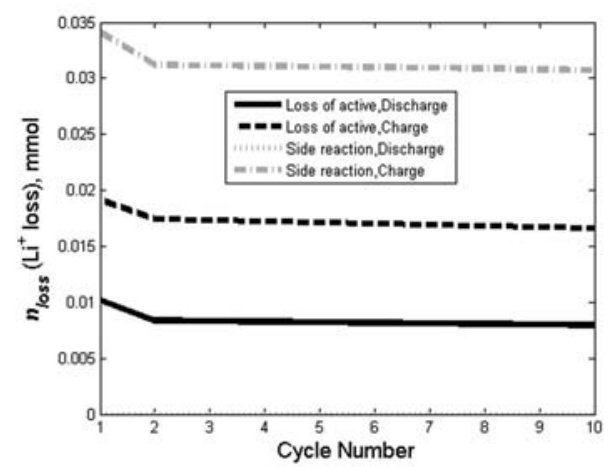

(d)

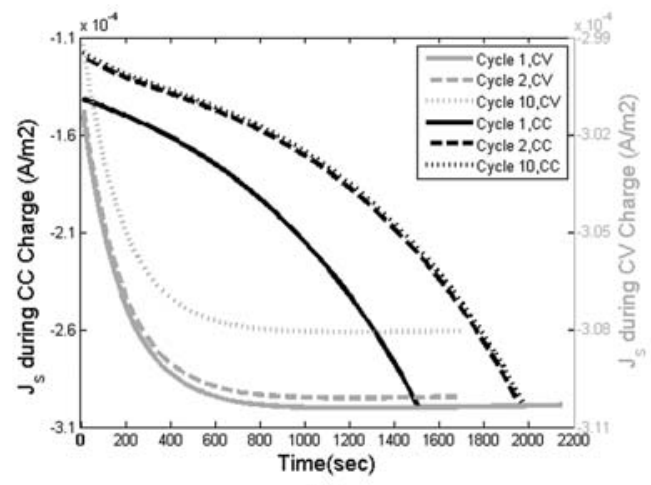

(e)

Figure 7. Case study 2 (a) Number of Li ions deintercalated from/intercalated into the cathode/anode in charge/discharge during the cell life (b) EODV and CC charge time versus cycle number (c/d) Loss of Li ions due to the side reaction and the loss of anode active material during the cell life/ the first 10 cycles (e) side reaction current density during the $\mathrm{CC}$ and $\mathrm{CV}$ charge for the first, second and tenth cycles. 
Table VI. Comparison of first, second and tenth discharge data for the purpose of describing Fig. $6 c$.

\begin{tabular}{ccccr} 
Cycle & $\Delta x_{n, a v g}$ & $\Delta \omega_{n}$ & $\Delta\left(\omega_{n} x_{n, a v g}\right)$ & $\Delta n_{L i^{+}, n}^{\text {discharge }}$ \\
\hline 1 & -0.53197 & -0.00023078 & -0.5320577 & 36.94778 \\
2 & -0.53231 & -0.00022957 & -0.5320316 & 36.94597 \\
10 & -0.53495 & -0.00022018 & -0.5320259 & 36.94557
\end{tabular}

spent under $\mathrm{CC}$ conditions is reduced. The loss of $\mathrm{Li}$ ions due to the film formation and the loss of anode active material are compared in Figs. 7c-7d which indicate that the majority of Li ions are lost due to the side reaction during the charge and there is no loss of $\mathrm{Li}$ ions during the discharge, due to the anode film formation. Moreover, the loss of $\mathrm{Li}$ ions due to the anode loss of active material during the charge is greater than the discharge owing to the longer total charge time. Fig. 7d shows the Li ions loss during the first 10 cycles occured for all cases (excluding the discharge loss due to the side reaction) characterized by a rapid drop during the second cycle and then the losses decreasing gradually for the remaining cycles. The rapid drop can be described by considering the side reaction current density during the $\mathrm{CC}$ and $\mathrm{CV}$ charge for the first, second and tenth cycles as shown in Fig. 7e. During the CC charge of the second cycle, the side reaction overpotential changes considerably due to the great increase in the $\mathrm{CC}$ charge time with respect to the first cycle. As a result, the side reaction current density values during the $\mathrm{CC}$ charge of the second cycle are greater than (less than in magnitude) the first cycles, making the capacity loss (integral of $J_{s}$ over time) increase about $0.201 \mathrm{Ah}$ which is less than as expected (the CC charge time increases greatly during the second cycle). On the other hand, during the CV charge of the second cycle, the side reaction current density values are a small amount greater than (less than in magnitude) the first cycle as shown in Fig. 7e (green dashed line) while the CV charge time drops remarkably during the second cycle causing the capacity loss decrease about $0.484 \mathrm{Ah}$. Thus, the capacity loss drops rapidly for the second cycle, and the loss of Li ions due to the film formation during the charge drops as well. However, during the remaining cycles the capacity loss per cycle during the charge decreases gradually due to the variation of the current density during the $\mathrm{CC}$ and the $\mathrm{CV}$ (Fig. 7e green and black dotted lines) as a consequence of the $\mathrm{CC}$ charge time change. The variation of the loss of $\mathrm{Li}$ ions due to the anode loss of material during the discharge (black solid line) can be clarified by studying the data in Table VI for the first, second and tenth cycles. Since the slope of the anode loading degradation, $\Delta \omega_{n}$, decreases with cycle number, the degradation change during the first cycle is greater in magnitude than the second cycle while the anode SOC alteration during the second cycle is greater than the first cycle due to smaller values of the degradation (see Eq. 2a). Nonetheless, the change of the product of the anode SOC and degradation becomes less as the cell dies resulting in the reduction of the Li ions loss whilst more drop is seen during the second cycle, because of the increase in the anode SOC change during the remaining cycles as presented in Table VI for the tenth cycle. Similarly, the change in the Li ions loss as a result of the anode degradation during the charge can be explained. Another point for case 2 is that since only the anode loses its active material, the limiting electrode is shifted from the cathode to the anode in cycle 83 when the anode loading reaches to $4.786 \mathrm{~g}$.

The EKF and the UKF results for the current and degradations' predictions are compared in Fig. 8 showing a good agreement between the predicted values and the true values for the UKF method while the EKF was not able to follow the data after a few cycles. Table V presents the maximum and the average values of the residuals and the computation time of both methods. Similar to the first case, the UKF greatly improved the results at the expense of longer CPU time.

Case study 3: anode side reaction and electrodes' loss of active material.-The same parameters of the anode film formation and degradation as the first and second case studies (Table I-II) are selected, yet the cathode is also degraded in this case using the param- eters in Table II. During the first discharge the cathode losses active material as well as the anode causing a greater increase in the cathode SOC than the other case studies (Table IIIa). The increase in cathode SOC makes the cathode OCP drop and as a result the EODV decreases more rapidly with respect to other cases as shown in Fig. 9a. The CC charge time decreases more than the second case due to loss of active material in both electrodes leading less increase in the SOCs at the beginning of discharge during the cell life (Table IIIb, c). As a result, the anode SOC at the end of discharge decreases more than the other cases causing the EODV drop more rapidly. Furthermore, at the end of discharge the cathode SOC increases more than the other

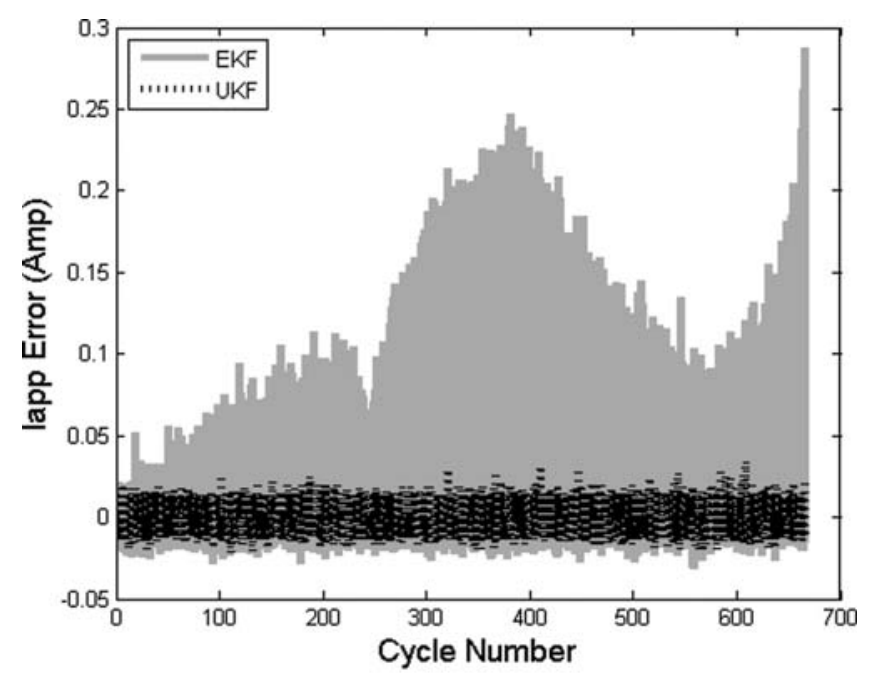

(a)

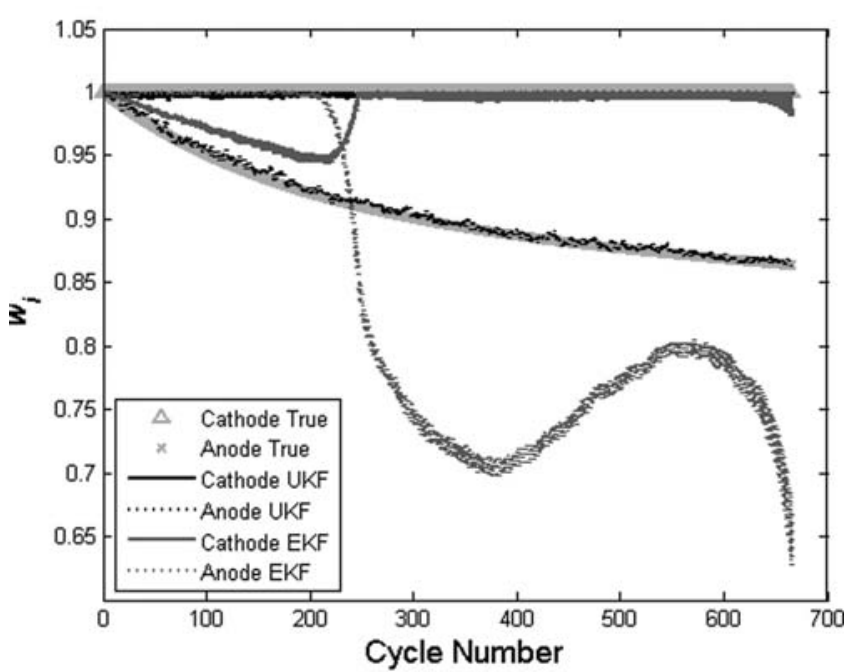

(b)

Figure 8. Case study 2, EKF and UKF comparison (a) applied current errors between the filtering and the synthetic data (b) degradations of the electrodes predicted by filtering and the synthetic data. 


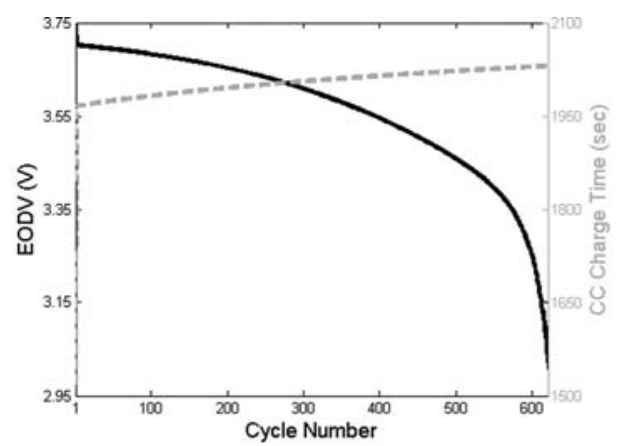

(a)

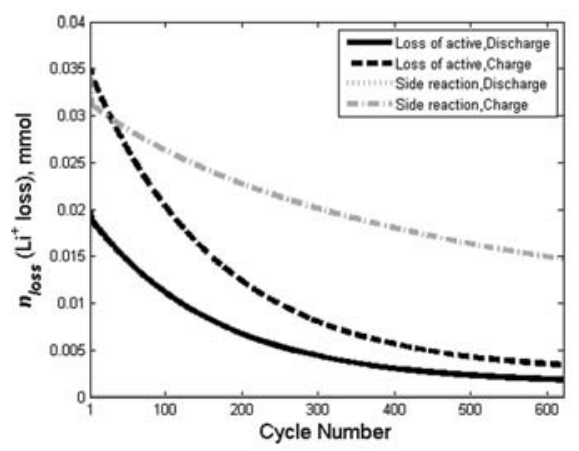

(c)

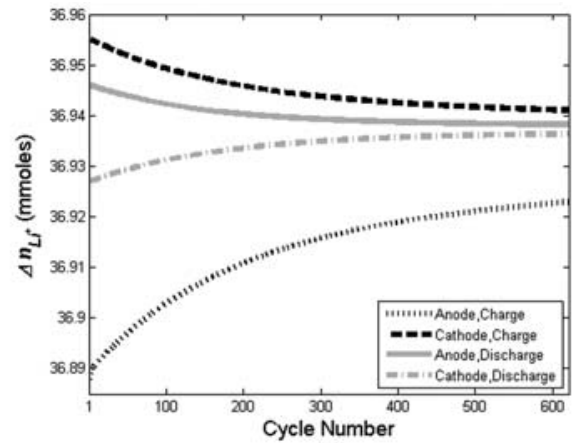

(b)

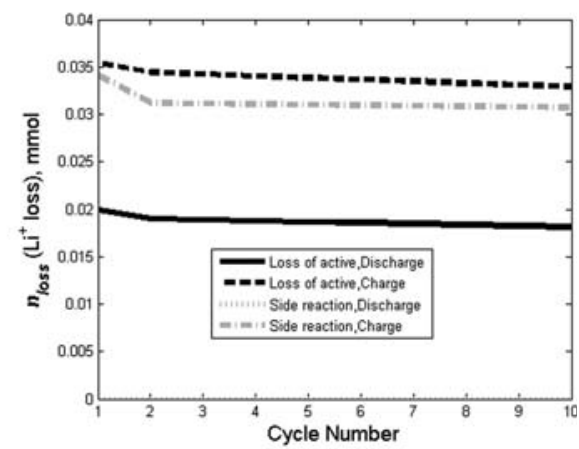

(d)

Figure 9. Case study 3 (a) EODV and CC charge time versus cycle number (b) Number of Li ions deintercalated from/intercalated into the cathode/anode in charge/discharge during the cell life (c/d) Loss of Li ions due to the side reaction and the loss of anode active material during the cell life/ the first 10 cycles.

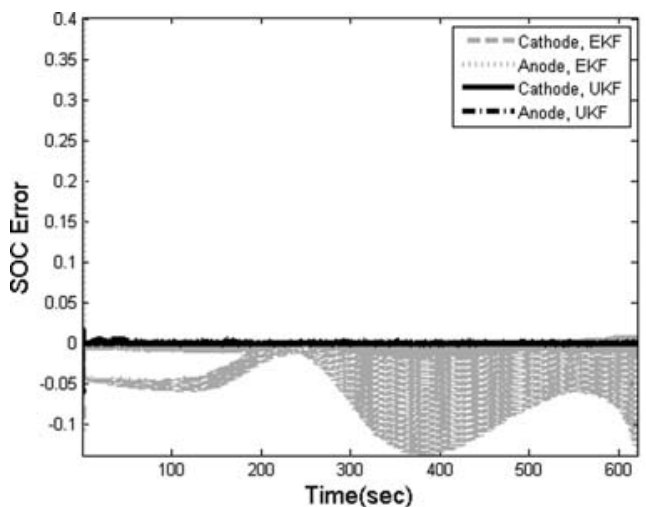

(a)

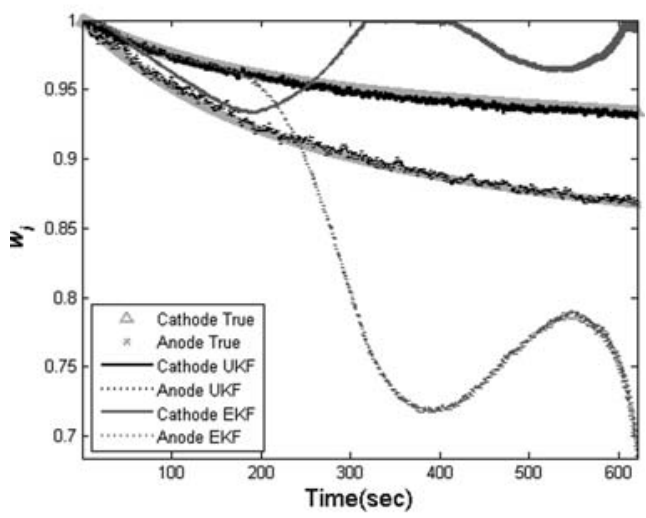

(b)

Figure 10. Case study 3, EKF and UKF comparison (a) electrodes' SOC errors between the filtering and the synthetic data (b) degradations of the electrodes predicted by filtering and the synthetic data using Eq. 11. case studies causing the additional drop in the EODV (Table IIIb, c). Fig. 9 shows the number of $\mathrm{Li}$ ions that depart from and diffuse into the electrodes and lost during the charge and discharge are shown in. Fig. 9b indicates that the number of ions intercalated into the cathode during the discharge is less than the other cases because some of ions are lost due to loss of the cathode active material. The same reason enhances the number of ions leaving the cathode during the charge with respect to other case studies. Including the cathode loss of active material raises the loss of $\mathrm{Li}$ ions and consequently diminishes the cell life to 621 cycles as shown in Figs. 9c-9d. Similar to case 2 the limiting electrode is shifted to the anode from the cathode because the anode degradation parameters are greater than the cathode (Table II). At cycle 207 when the cathode and the anode loadings are $12.47 \mathrm{~g}$ and $4.59 \mathrm{~g}$ respectively, the anode is the limiting electrode. The results of the filtering techniques are shown in Fig. 10 and Table V validating that the UKF approach is a good candidate for the prediction of the $\mathrm{SOC}$ and the capacity loss mechanism for $\mathrm{Li}$ ion batteries cycling. The remarkable point in this case is that, the UKF CPU time is shorter (about $0.3 \mathrm{sec} / \mathrm{cycle}$ ) than the EKF due to divergence of the EKF in most cycles where the integrator were compelled to choose a very small step size.

\section{Conclusions}

Three different capacity loss mechanisms have been studied in detail for a $\mathrm{Li}$ ion cell under LEO cycling conditions by means of the physics-based SP model. The first case considered only the anode film formation as a side reaction that depletes the number of $\mathrm{Li}$ ions deintercalated into the negative electrode during the charge causing the anode SOC and thereby the EODV drop as the cell was cycled. For the next case study, the anode loss of active material was added to the SP model as an additional reason of the capacity fade during the cell life, resulting in more loss of Li ions during the charge and also some of the $\mathrm{Li}$ ions are lost during the discharge. As a result, the anode OCP at the end of discharge increased rapidly due to more reduction of the anode SOC causing the EODV drop below $3.0 \mathrm{~V}$ in 
308 cycles less than the first case. Finally, the cathode degradation was regarded as the third factor of the cell capacity loss. The loss of active material inside the electrodes increases the current density and the SOC variation of both electrodes during the discharge because the discharge rate and duration is constant in LEO condition. Thus, the loss of cathode active material results in the cathode SOC increasing more than the other cases and accordingly the cell dies faster.

We also tried to estimate the electrodes' degradation rates as well as the SOCs for all three case studies by applying the nonlinear Kalman Filtering approaches. The EKF and the UKF methods were selected as the candidates for the state estimation by using the SP model with the same parameters. However, only a process noise was considered as the RHS of the state equations for the degradation of both electrodes. Moreover, the initial SOC of both electrodes were altered 10\% from the true values in order to examine the capability of the proposed method. The results demonstrated that the UKF approach was able to predict the data successfully while the EKF diverged in all case studies due to the linearization. Tracking the true loading electrodes' degradations by the UKF for the cases studied enabled us to determine which degradation mechanism causes the loss of $\mathrm{Li}$ ions in reasonable computation time.

\section{Acknowledgments}

The authors acknowledge MDA for sponsoring this work through Quallion LLC STTR Phase I contract \# HQ0147-11-C-7664.

\section{Appendix A}

The $\mathrm{Li}$ ion mole balance for a spherical electrode (according to the SP model assumption) takes the following form:

$$
\frac{d}{d t}\left(V_{i} c_{i, a v g}\right)=-N_{L i}+A_{i}
$$

where $c_{i, a v g}$ is the average concentration of $\mathrm{Li}$ ion inside the electrode, and $\mathrm{N}_{\mathrm{Li}+}$ is the flux of the $\mathrm{Li}$ ion that goes into or leaves the electrode ${ }^{23}$ :

$$
\begin{aligned}
& N_{L i}+=\frac{I_{a p p}}{F S_{i}} \\
& S_{i}(t)=\frac{3 l_{i}(t)}{R_{i} \rho_{i}}
\end{aligned}
$$

where $I_{a p p}$ is the applied current to the cell and $S_{i}$ is the electroactive surface area in the electrode. $V_{i}$ and $A_{i}$ are the volume and surface area of each electrode consisting of spherical closely packed particles:

$$
\begin{aligned}
V_{i} & =\frac{4}{3} \pi R_{i}^{3} \\
A_{i} & =4 \pi R_{i}^{2}
\end{aligned}
$$

where $R_{i}$ is the radius of the spherical electrode. By substituting Eqs. 23-24 in Eq. 22 and simplifying we have:

$$
\frac{d}{d t}\left(c_{i, a v g}\right)=-\frac{3 I_{a p p}}{F S_{i}(t) R_{i}}
$$

By considering the following expressions Eq. 1a can be obtained:

$$
\begin{aligned}
& x_{i, a v_{g}}=\frac{c_{i, a v g}}{c_{i, \max }} \\
& S_{i}(t)=\omega_{i}(t) S_{i}^{0}
\end{aligned}
$$

where $S_{i}^{0}$ is the initial active surface area of the electrode.

\section{Appendix B}

In this appendix, functions $f, g$ and $h$ defined in Eq. 17 for different LEO steps are expressed in terms of the model equations:

\section{Constant Current Discharge}

Since no side reaction occurred during the discharge, the DAE system can be simplified to the ODE system (Eqs. 18-19). The state variables are the electrodes' SOCs and loading degradations while the electrodes' surface concentrations and potentials are

considered as the algebraic variables. The cell voltage is the measurement variable. Thus, functions $f, g$ and $h$ are given as follows:

$$
\left\{\begin{array}{c}
f=\left[\begin{array}{c}
\frac{-15 D_{s, p}}{R_{p}^{2}}\left(x_{p, a v_{g}}-x_{p, \text { surf }}\right) \\
\frac{-15 D_{s, n}}{R_{n}^{2}}\left(x_{n, a v g}-x_{n, \text { surf }}\right) \\
0 \\
0
\end{array}\right] \\
g=\left[\begin{array}{l}
x_{p, \text { surf }}-x_{p, a v g}+\frac{J_{p} R_{p}}{5 F D_{s, p} c_{p, \max }} \\
x_{n, \text { surf }}-x_{n, a v g}+\frac{J_{n} R_{n}}{5 F D_{s, n} c_{n, \max }} \\
\phi_{p}-U_{p}^{\theta}-\eta_{p} \\
\phi_{n}-U_{n}^{\theta}-\frac{I_{a p p}}{S_{n}} R_{f i l m}-\eta_{n}
\end{array}\right] \\
h=\phi_{p}-\phi_{n}+I_{a p p} R_{c e l l}
\end{array}\right.
$$

where the overpotentials are obtained using Eq. $7 .^{30}$

\section{Constant Current Charge}

In this step, the film thickness and the side reaction over potential are required to append to the discharge state and algebraic variables respectively. The following expression is needed to include in the discharge $f$ vector for the film thickness (Eq. 6):

$$
f_{5}=\frac{-J_{s} M_{f}}{\rho_{f} F}
$$

where $J_{s}$ is obtain by Eq. 3 . Note that the film thickness is not considered as a state needed to be estimated using filtering methods in this work. As a result, the same function for the discharge is used for the charge in filtering approaches. The first three elements of the discharge $g$ vector are the same for CC charge while the sign of the film resistance term in the last element is required to change to positive. The algebraic expression for the side reaction over potential is considered as the last element (Eq. 4) of the $g$ vector:

$$
g_{5}=\phi_{n}-U_{r e f, f}+\frac{I_{a p p}}{S_{n}} R_{f i l m}-\eta_{s}
$$

The $h$ function is the same as the discharge $h$ function.

\section{Constant Voltage Charge}

The same $f$ and $g$ functions as CC charge are used for $\mathrm{CV}$ charge while the $h$ function is updated because the measurement variable is the current:

$$
h=\frac{V_{\text {cell }}-\phi_{p}+\phi_{n}}{R_{\text {cell }}}
$$

\section{List of Symbols}

$A_{i}$

$c_{e}$

$c_{i, \max }$

chol

$d f_{i, 1}$

$d f_{i, 2}$

diag

$D_{s, i}$

$E$

$F$

$f$

$g$

$h$

$H$

$I_{a p p}$

$I_{C V}$
Electrode surface area $\left[\mathrm{m}^{2}\right]$

Electrolyte concentration $\left[\mathrm{mol} / \mathrm{m}^{3}\right.$ ]

Maximum solid phase concentration for each electrode $(i=p, n)\left[\mathrm{mol} / \mathrm{m}^{3}\right]$

Cholesky factorization operator

Electrode degradation factor $(i=p, n)$

Electrode degradation factor $(i=p, n)$

Diagonal matrix operator

Solid phase diffusion coefficient of $\mathrm{Li}^{+}$for each electrode $(i=p, n)\left[\mathrm{m}^{2} / \mathrm{s}\right]$

Expected Operator

Faraday constant $[\mathrm{C} / \mathrm{mol}]$

Nonlinear function for differential state variables

Nonlinear function for algebraic state variables

Nonlinear function for output variables

Jacobian of $h$

Applied Current [C/s]

Current during the $\mathrm{CV}$ charge $[\mathrm{C} / \mathrm{s}]$ 
$i_{O f}$

J

$J_{i}$

$J_{s}$

k
Exchange current density for the film formation reaction $\left[\mathrm{A} / \mathrm{m}^{2}\right]$

Jacobian of $f$

Current density for each electrode $\left[\mathrm{A} / \mathrm{m}^{2}\right](i=p, n)$

Side reaction current density $\left[\mathrm{A} / \mathrm{m}^{2}\right]$

Time Index

Film specific conductivity [S/m]

Rate constant for each electrode $(i=p, n)$

$\left[\mathrm{A} \mathrm{m}{ }^{2.5} / \mathrm{mol}^{1.5}\right.$ ]

Filter Gain

Electrode loading $(i=p, n)[\mathrm{Kg}]$

Initial electrode loading $(i=p, n)[\mathrm{Kg}]$

Molecular weight of the film $[\mathrm{g} / \mathrm{mol}]$

$\mathrm{LiCoO}_{2}$ molecular weight $[\mathrm{g} / \mathrm{mol}]$

Number of state variables

Flux of $\mathrm{Li}$ ions $\left[\mathrm{mol} / \mathrm{m}^{2} \mathrm{~s}\right]$

Loss of $\mathrm{Li}$ ions due to the side reaction [mol]

Total loss of Li ions [mol]

Total cyclable Li ions [mol]

State covariance matrix

Measurement covariance matrix

Process covariance matrix

Diagonal of $Q$ Matrix

Measurement covariance matrix

Gas constant $[\mathrm{J} / \mathrm{mol} / \mathrm{K}]$

Cell resistance $[\Omega]$

Film Resistance $\left[\Omega \mathrm{m}^{2}\right]$

Particle radius for each electrode $(i=p, n)$ [m]

Resistance of the Solid Electrolyte Interphase layer $\left[\Omega \mathrm{m}^{2}\right]$

Electroactive surface area for each electrode

$(i=p, n)\left[\mathrm{m}^{2}\right]$

Temperature $[\mathrm{K}]$

Time [sec]

Characteristic time for the degradation [sec]

Input variable, applied cell current during $\mathrm{CC}$ charge and discharge and cell voltage during CV

Open circuit potentials for each electrode $(i=p, n)$

[V]

Open circuit potential for the film formation reaction

[V]

Measurement zero-mean Gaussian noise

Cell voltage [V]

Electrode's Volume $(i=p, n)\left[\mathrm{m}^{3}\right]$

Process zero-mean Gaussian noise

UKF weights

Differential state variable

Output variable, cell voltage during $\mathrm{CC}$ charge and discharge and applied cell current during CV

Algebraic variable e.g. electrode potentials, solid surface concentrations

Ratio of the solid average concentration to the maximum solid concentration for each electrode $(i=p, n)$ (SOC)

Ratio of the solid surface concentration to the maximum solid concentration for each electrode $(i=p, n)$ Sigma points for state variables

Algebraic variables vector

Sigma points for measurement variables

UKF tuning parameter $\beta$

$\alpha_{a, i}$

$\alpha_{c, i}$

$\alpha_{c, f}$

$\gamma$

$\kappa$

$\lambda$

$\delta$

$\delta_{f i l m}$

$\eta_{i}$

$\eta_{s}$

$\rho_{i}$

$\rho_{f}$

$\phi_{i}$

$\omega_{i}$
UKF tuning parameter

Cathodic transfer coefficient for the deintercalation/intercalation reactions

Anodic transfer coefficient for the deintercalation/intercalation reactions

Cathodic transfer coefficient for the film formation reaction

UKF scaling parameter

UKF tuning parameter

UKF parameter

Dirac function

Film thickness [m]

Overpotentials for the lithium ion deintercalation/intercalation reactions for each electrode $(i=p, n)[\mathrm{V}]$

Side reaction over potential [V]

Density of active material $(i=p, n)\left[\mathrm{Kg} / \mathrm{m}^{3}\right]$

Film density $\left[\mathrm{Kg} / \mathrm{m}^{3}\right]$

Electrode's potential $(i=p, n)[\mathrm{V}]$

Degradation of loading for each electrode $(i=p, n)$ $\left(\omega_{i}=\frac{l_{i}(t)}{l_{i}^{0}}\right)$

\section{References}

1. M. W. Verbrugge and R. S. Conell, J. Electrochem. Soc., 149, A45 (2002).

2. M. W. Verbrugge and E. Tate, J. Power Sources, 126, 236 (2004).

3. M. W. Verbrugge, P. Liu, and S. Soukiazian, J. Power Sources, 141, 369 (2005).

4. M. W. Verbrugge and B. Koch, J. Electrochem. Soc., 153, A187 (2006).

5. G. Plett, J. Power Sources, 134, 252 (2004).

6. G. Plett, J. Power Sources, 134, 262 (2004).

7. G. Plett, J. Power Sources, 134, 277 (2004).

8. G. Plett, J. Power Sources, 161, 1356 (2006).

9. G. Plett, J. Power Sources, 161, 1369 (2006).

10. J. Lee, O. Nam, and B. H. Cho, J. Power Sources, 174, 9 (2007).

11. Y. Hu, S. Yurkovich, Y. Guezennec, and B. J. Yurkovich, Control Eng. Particle, 17, 1190 (2009).

12. F. Sun, X. Hu, Y. Zou, and S. Li, Energy, 36, 3531 (2011).

13. S. Santhanagopalan and R. E. White, J. Power Sources, 161, 1346 (2006).

14. S. Santhanagopalan and R. E. White, International J. of Energy Research, 34, 152 (2010).

15. K. A. Smith, C. D. Rahn, and C. Y. Wang, IEEE Trans. on Control Systems Tech., 18, 654 (2010).

16. D. D. Domenico, A. Stefanopoulou, and G. Fiengo, J. of Dynamic Systems, Measurement, and Control, 132, 061302 .

17. B. S. Haran, B. N. Popov, and R. E. White, J. Power Sources, 75, 56 (1998).

18. S. Santhanagopalan, Q. Guo, and R. E. White, J. Electrochem. Soc., 154, A198 (2007).

19. L. Cai and R. E. White, J. Power Sources, 196, 5985 (2011).

20. C. Y. Wang, W. B. Gu, and B. Y. Liaw, J. Electrochem. Soc., 145, 3407 (1998).

21. P. Ramadass, B. Haran, P. M. Gomadam, R. E. White, and B. N. Popov, J. Electrochem. Soc., 151, A196 (2004).

22. Q. Zhang and R. E. White, J. Power Sources, 179, 793 (2008).

23. S. Santhanagopalan, Q. Guo, and R. E. White, J. Electrochem. Soc., 154, A198 (2007).

24. J. W. Lee, Y. K. Anguchamy, and B. N. Popov, J. Power Sources, 162, 1395 (2006).

25. M. S. Grewal and A. P. Andrews, Kalman Filtering: Theory and Practice Using MATLAB, J. Wiley \& Sons, Inc., NJ 2008.

26. R. van der Merwe, "Sigma-Point Kalman Filters for Probabilistic Inference in Dynamic State-Space Models," Oregon Health \& Science University, OR, 2004.

27. J. L. Crassidis and J. L. Junkins, Optimal Estimation of Dynamic Systems, Chapman \& Hall/CRC Applied Mathematics and Nonlinear Science Series, NY, 2004.

28. S. Julier and J. K. Uhlmann, Proceedings of the IEEE, 92, 401 (2004).

29. R. Kandepu, B. Foss, and L. Imsland, J. of Process Control, 18, 753 (2008).

30. S. Khaleghi Rahimian, S. Rayman, and R. E. White, J. Power Sources, 196, 8450 (2011).

31. S. Santhanagopalan, Q. Guo, P. Ramadass, and R. E. White, J. Power Sources, 156, 620 (2006). 